https://helda.helsinki.fi

\title{
Digital currencies in financial networks
}

\section{Castrén, Olli}

European Banking Authority

2020-07-02

Castrén , O , Kavonius , I K \& Rancan , M 2020 ' Digital currencies in financial networks '

European Banking Authority Staff Paper Series , no. 8 , vol. 2020 , European Banking

Authority , Paris , pp. 1-49 . https://doi.org/10.2853/8297, https://doi.org/10.2139/ssrn.3749352

http://hdl.handle.net/10138/317766

https://doi.org/10.2853/8297

unspecified

publishedVersion

Downloaded from Helda, University of Helsinki institutional repository.

This is an electronic reprint of the original article.

This reprint may differ from the original in pagination and typographic detail.

Please cite the original version. 


\section{DIGITAL CURRENCIES IN FINANCIAL NETWORKS}

by Olli Castrén, Ilja Kristian Kavonius and Michela Rancan 


\section{ABSTRACT}

We introduce a digital currency, either as a central bank digital currency (CBDC) or a financial crypto asset (stablecoin), in the network of financial accounts. Simulating a shift of deposits by both households and non-financial corporations from the banking sector to the digital currency, we model the different responses of the affected institutional sectors. We find that the introduction of a digital currency generates significant adjustments in the balance sheets of all sectors, may trigger large moves in securities prices and induces changes in the network structure. The economic impacts vary depending on the design of the digital innovation, the size of the deposit shift, the channels through which the balance sheet adjustments take place and the timing of the initiative.

\section{KEYWORDS}

Digital Currency, Central Bank Digital Currency, Stablecoins, Macro-network, Financial Intermediation, Financial

Stability. JEL Classification: G21, E58 


\section{Introduction}

Digital currencies have the potential to substantially re-shape the future of banking and financial intermediation. Whether the provision of a digital currency is by the public sector (central bank digital currency, CBDC) or a by a private initiative (narrowly referred to in this paper as a stablecoin), the eventual rollout of such new instruments is likely to provide a significant boost to the retail use of digital assets. At the same time, financial innovations may create new risks and vulnerabilities whose implications should always be thoroughly assessed. This paper analyses the introduction of digital currencies in the network of financial accounts. We identify key channels through which the effects of these novel instruments propagate in the network, and we reveal significant direct and indirect consequences for most parts of the financial system.

The international monetary and regulatory community has initiated work on several fronts to prepare for an orderly transition to digital currencies (see, e.g., G7, 2019; BIS, 2019; Basel Committee, 2019; FSB, 2019). While the importance of financial innovation per se is commonly recognised, these reports also highlight new threats to financial stability and call for a regulatory response. Among the potential risks of a disorderly transition is the possibility that, depending on the ultimate role of existing financial intermediaries, the commercial banking system may experience the intractable loss of its fee-generating payment business, erosion of retail deposit funding and disintermediation of its core lending functions, with adverse consequences for the efficient allocation of credit to the economy. Additional risks not considered in this paper are associated with money laundering and digital dollarization. Careful planning and coordination among all the relevant parties seems essential to prevent damaging disruptions.

A rapidly growing body of academic literature is devoted to the study of the design and implications of digital currencies. Theoretical models include Andolfatto (2018), Kim and Kwon (2018), Agur et al. (2019), Keister and Sanches (2019), Brunnermeier and Niepelt (2020) and Fernandez-Villaverde et al. (2020). These authors investigate, with sometimes conflicting results, the effects of different digital currency designs on bank lending and banks' deposit market power, cost of funding and aggregate welfare. On the more conceptual side, Brunnermeier et al. (2019) discuss the effect of these instruments on models of monetary exchange and currency competition. Moreover, Adrian and Mancini-Griffoli (2019) propose a conceptual framework to categorise digital monies, and Bullmann et al. (2019) provide a taxonomy of the various models of private digital currencies. In a quasi-empirical approach using financial balance sheets, Kumhof and Noone (2018), in turn, study the introduction of CBDC and derive a set of "core principles" that could prevent runs from retail deposits to CBDC. Finally, Bindseil (2020) analyses the system-wide impact of both a CBDC and private digital currencies and argues that a two-tiered remuneration system may be sufficient to mitigate the risk of retail deposit runs to the CBDC.

Our starting point is the introduction of a digital currency in financial accounts. An important challenge in using balance sheets is that, to date, no official consensus exists on the classification of digital currencies in national accounts statistics. We provide a critical review of the discussion and propose a statistical allocation for the digital financial assets that are considered in this paper. More specifically, we consider a CBDC as a deposit scheme similar to the existing central bank deposit facilities, but with an extended list of counterparties, including non-financial agents. We classify stablecoins either as a new deposit instrument, termed "non-MFI deposits", or a collective investment scheme where the digital instrument is a UCIT-type investment fund share.

Armed with these definitions, we build on the work in Castrén and Kavonius (2013) and Castrén and Rancan (2014) and incorporate the new financial assets into the "Macro-Network", a network of bilateral exposures among the institutional sectors of the economy. We model the introduction of a digital currency as a deposit shift out of commercial banks to the digital currency. Then, under the different designs, we model a set of reactions from the sectors affected by the deposit shift, focusing on the banking sector and the implications that its adjustment may have on the other sectors. We find that in the process of balance sheet adjustments, the heterogeneous portfolios of bonds and loans held by the different sectors mean that the set of assets (securities 
or loans) that one sector may have to sell is not the same as the set of assets that another sector may be willing to buy. ${ }^{1}$ Price adjustments are then required to allow the markets to clear. ${ }^{2}$

Shock simulations give rise to the following main findings. First, we identify the key channels through which the impact of the introduction of digital currencies propagates to the main sectors of the economy. We show that even a relatively limited loss of deposits is sufficient to trigger major adjustments in banking-sector balance sheets, which, in turn, have implications for other sectors, including the "rest of the world" sector and, thereby, foreign residents and institutions. When the banking sector adjusts to a funding gap by redeeming loans, households experience the largest impact. When the banking sector reacts, instead, by selling securities, nonfinancial corporations are most affected. Our framework is flexible and capable of accounting for any securities portfolio structures and rules that govern the adjustment of the accounts of the various sectors.

Second, by invoking network centrality measures, we observe changes in the relative importance of the individual nodes of the network (the institutional sectors). The introduction of a CBDC or stablecoin will cause the sector issuing the digital currency to become a more central player in the network at the expense of the banking sector, but the process also has important consequences for third parties, such as the "rest of the world" sector. By affecting the shape of the macro network, the introduction of a digital currency may also affect the network's stability properties. Our findings therefore also support the view that the regulation of digital currencies should take into account wider effects than just the immediate counterparty exposures. Finally, we show that because the key properties of financial networks are time-varying, it is not only the design of a digital currency but also the timing of its launch that matter in terms of the impact on the financial system.

The remainder of this paper proceeds as follows. First, Section 2 presents the data, after which Section 3 proposes an allocation of the different types of digital currencies into the financial accounts. Then, Section 4 introduces the methodology and the macro-network approach to modelling financial interlinkages, with a formal model relegated to the Annex. Next, Section 5 includes the simulation exercises to assess the dynamic impact of the introduction of a digital currency. Section 6 then generalises the results by looking at different shock sizes and assesses the time varying impact on network structures. Section 7 concludes.

\footnotetext{
${ }^{1}$ In Kumhof and Noone (2018), Juks (2018) and Bindseil (2020), shocks to individual sectors' asset and liability positions are immediately rebalanced by offsetting shifts in homogeneous asset and liability items. These models implicitly assume that there is only one type of financial asset (a bond, an equity share or a bank loan) that can be exchanged in the account rebalancing process. Our framework accounts for the existing heterogeneity in the portfolios of the different sectors.

${ }^{2}$ An alternative would be to allow for several additional rounds of rebalancing where the process ultimately converges to a new steady state. Since our focus is on the immediate effects of the introduction of a digital currency, we limit the contagion analysis to only the first stages of the process. The algorithms can be easily adjusted to cover several additional rounds of contagion. Another possibility is to assume that the affected parties absorb the shocks in their equity/net wealth positions. In this case, however, the shocks merely shift to the non-financial side of the economy via the net lending position that connects the financial accounts to the non-financial accounts. The shock would then affect the sectors' saving/investment positions.
} 


\section{Data}

We use data on sector-level financial accounts - often referred to as flow of funds - from the Euro Area Accounts (EAA), published jointly by the ECB and Eurostat. In the EAA, the analytical grouping of economic agents into institutional sectors and transactions follows the methodological framework established in the European System of Accounts 2010 (ESA2010, the European application of the 2008 System of National Accounts, SNA2008). Ten distinct institutional sectors are considered: households, including non-profit institutions serving households $(\mathrm{HH})$, nonfinancial corporations (NFC), banks (monetary financing institutions, MFI), the central bank (CB), insurance companies (INS), pension funds (PF), other financial intermediaries (OFI), non-money-market-fund investment funds (INV), general government (GOV), and the rest of the world (RoW). Owing to the inclusion of the rest of the world sector, the asset and liability items also include instruments originating from foreign counterparties. Together, these sectors cover the complete financial accounts of the domestic economy, and, by including the RoW sector, the system is closed, i.e. each financial asset item that is held by a sector has a counterparty item on the liability side of some other sector. ${ }^{3}$ The categories of financial instruments that constitute the sector-specific balance sheets are distinguished in the ESA2010 and are classified according to liquidity factors and legal characteristics. The analysis in this paper covers the following instrument types: currency, deposits, debt securities, loans and investment fund shares. The EAA provide who-to-whom tables, i.e. the cross-sector bilateral financial exposures, for all these instruments categories, from 2015 Q1 onwards. The full data is available at the ECB Statistical Warehouse.

\section{Allocating Digital Currencies within Financial Accounts}

Despite of the potential for digital currencies to play an important role in the future of banking and finance, allocating these instruments within the system of financial accounts, or in regulatory or accounting standards, is not a straightforward task. ${ }^{4}$ This is not least because there are many forms and types of digital assets, and any classification of a specific design would ultimately need to be on a case-by-case basis. In terms of national accounts classifications, no clear consensus has yet emerged on the particular financial instrument categories under which digital assets should be recorded. Since a realistic allocation of these instruments within the network of exposures is crucial for the relevance of our analysis below, we devote some space to that discussion.

\footnotetext{
${ }^{3}$ Note that in the financial accounts, the RoW sector is not a "residual" sector; rather, it has its own sources and accounts that are calculated independently, as in the case of any other sector, describing both domestic residence units' assets and liabilities abroad or foreign residence units' assets and liabilities in the domestic economy. The EAA data are nonconsolidated, which means that they include financial links not only between the sectors but also within the sectors in the system.

${ }^{4}$ National accounts manuals are only revised at low frequencies (typically once every 10 years), and treating new phenomena therefore requires interim solutions. National accounts revisions are to the extent possible also coordinated with changes in regulatory and accounting standards.
} 
At the heart of the issue is the question of whether digital assets and crypto assets can be considered financial assets, or indeed assets at all. The statistical definition of an asset is that it is owned by an entity that should derive economic benefits from holding it. The OECD (2018) argues that for digital/crypto instruments this ownership condition is generally met (for example, in the form of the possession of the crypto keys). Because digital instruments, in addition, also allow value to be carried forward between accounting periods, they can thus be considered assets. The definition of financial assets, a necessary condition for our analysis, is more challenging. National accounts manuals state that an asset is financial when there is a corresponding claim to another institutional entity which entitles the holder of the asset to receive an agreed payment on an agreed date. The requirement of an issuing entity, to whom the instrument is a liability item, excludes from the definition of financial assets all items that are "discovered" or "mined", such as Bitcoin. By contrast, the definition would encompass central-bank-issued digital assets because these establish a liability to the central bank that can be held by non-financial counterparties in a similar way to other central bank money (cash and banknotes) at present. ${ }^{5}$ For some types of privately initiated digital currencies with a link to an asset, such as stablecoins, this definition of a financial asset also seems readily applicable. This seems particularly true for stablecoins which, for the purposes of this paper, are considered fully backed by a reserve fund. This, in theory, allows the holders to liquidate their tokens at any point in time and at no cost. By contrast, crypto assets with no corresponding liability item are, as a rule, excluded from financial assets and are instead classified as nonfinancial assets or intangible assets. ${ }^{6}$

Our allocation proposal starts with a general classification of the high-level concepts presented above. The term "digital asset" here incorporates central bank digital currencies (CBDCs) and all types of non-official sector crypto assets. The term "crypto asset" is a subcategory of "digital asset" and encompasses both non-issued assets (nonfinancial assets, such as Bitcoin) and issued assets (financial assets, considered here under the generic term "stablecoin"). Given the focus of this paper on digital currencies as financial assets, we consider only the latter types of crypto assets. Thus, in our paper the concept "digital currency" henceforth includes only CBDCs and stablecoins.

The next step is to identify the financial instrument categories under which CBDCs and stablecoins could be recorded. This choice is important, since it has implications also for the prospective accounting and regulatory treatments of the named assets. As will be shown in Section 5 of this paper, this choice may also have broader financial system implications, given that the networks of financial exposures look quite different for different types of instruments. The most prominent options for instrument classification, with their respective advantages and disadvantages, can be summarised as follows (see also IMF, 2019 and OECD 2018). Note that options (i) and (ii) apply to both publicly and privately issued digital currencies (CBDCs and stablecoins), whereas options (iii) and (iv) only apply to private initiatives.

(i) Digital assets as currency. The general definition of a currency tends to overlap with the economic definition of money: an asset that serves as a means of exchange, store of value and unit of account. On these grounds, a CBDC clearly qualifies as a currency, given that it would either substitute for other forms of existing currency or would be an additional form of such, backed by the power of the sovereign. In contrast, some scholars are hesitant to allow private digital initiatives to obtain the status of a currency. It seems relatively straightforward to justify such objections in the case of non-financial crypto assets, but the argument may become weaker in the case of stablecoins.

\footnotetext{
${ }^{5}$ The OECD (2018) provides a brief conceptual discussion on whether modern fiat currencies issued in fractional reserve systems and not tied to a physical commodity, such as gold, actually pass the test of a financial asset that requires a contractual obligation to provide a payment upon redemption of the given monetary unit. They conclude that an assessment of the decisive criteria for recording fiat currencies as financial instruments is first required to see how the same criteria would relate to crypto assets and digital currencies. They also argue that if digital/crypto instruments were found to meet such criteria, these assets should be treated similar to fiat currencies but recorded in a separate subcategory to clearly distinguish them from the latter.

${ }^{6}$ One type of asset, namely monetary gold, has no liability item yet is classified as a financial asset. In the future, a similar exemption could also be considered for Bitcoin-like crypto assets with no issuing counterparty.
} 
Examples can be found where existing fiat currencies periodically failed to satisfy some of the definitions of money, and equal treatment would then require that stablecoins should not be excluded as such (see OECD, 2018). The objections towards classifying stablecoins as a currency also have an important political dimension, whereby the proponents of the status quo tend to associate the issuance of legal tender with the privilege of the sovereign authority (central bank and government).

Digital assets as deposits. Deposits are non-negotiable contracts that promise to pay out in full, either on demand (call deposits) or at an agreed maturity (time deposits). Again, a CBDC seems to qualify, not least because central banks already provide these types of accounts for eligible counterparties at overnight maturity. Establishing new central bank accounts for eligible counterparties that extend to non-financial entities (firms and retail depositors) therefore seems a straightforward way to introduce a CBDC. For private initiatives, the complexity arises from the fact that in the present financial accounts deposits can only be issued by a government, central bank or other monetary financing institutions (deposit-taking institutions). To qualify for the latter, an institution must possess a banking licence with all its obligations, including participation in deposit guarantee schemes and being subject to prudential rules and regulations. ${ }^{7}$ One possibility would be to introduce a new type of instrument, a "non-MFI deposit", with potentially lighter requirements, such as those currently applied to e-money institutions. ${ }^{8}$

(iii) Digital assets as securities. The IMF (2019) has considered the issue of "asset tokens", which include stablecoins, and has proposed that they be classified as debt or equity securities. ${ }^{9}$. While such an approach could be supported by some accounting proposals, several problems may arise from considering stablecoins as securities. On the one hand, debt securities must demonstrate characteristics of transferability which are not automatically met for crypto assets, even when backed by a reserve fund. On the other hand, equity establishes a claim on the residual value of a firm's assets. It is not clear if the holder of a digital token necessarily has such a claim vis-à-vis the stablecoin issuer.

(iv) Digital assets as units issued by collective investment schemes (UCITs). Another possibility for classifying stablecoins is to use the existing investment fund rules that incorporate schemes with stablecoin-like structures. ${ }^{10}$ For example, exchange traded funds (ETFs) hold the reference assets at a separate custodian institution and are supported by market-making "authorised participants". The role of these entities is to create and redeem ETF shares according to supply and demand conditions and to arbitrage away any differences between the value of the reference assets and the price of the ETF shares. In the case of some prominent stablecoin proposals, a set of "authorised resellers" would create and redeem digital tokens to equalise the value of the stock of tokens and the value of the reserve fund. ${ }^{11}$

\footnotetext{
7 The Swiss Financial Market Authority (FINMA, 2019) has issued specific guidelines for the classification of stablecoins. According to these guidelines, a stablecoin is considered a deposit scheme if the reserve fund is in a fiat currency or a basket of fiat currencies where the FX risk accrues to the stablecoin issuer. Current FINMA exemptions to the banking licence would apply if the stablecoin obtains deposits from banks, regulated institutions or investors with a professional treasury operation.

${ }^{8}$ For digital initiatives that mainly operate in the payment area requirements are in place to help ensure the continuing functioning of the deposit taking/repayment functions. For e-money institutions prudential requirements are intended to support redeemability at par.

${ }^{9}$ However, in Annex 2 of the same document, the IMF states that in financial accounts, non-central bank issued digital currencies could also be classified under "currency and deposits".

${ }^{10}$ The FINMA (FINMA, 2019) classification specifically includes such an option, stating that stablecoins with reserve assets invested either in non-cash, like securities, or in a basket of fiat currencies but with the FX risk accruing to the the stablecoin holder are classified as a collective investment scheme.

${ }^{11}$ See Libra Association (2019). Somoza and Terraciano (2019) argue that modelling stablecoins as a UCIT/ETF scheme would prevent these initiatives from interfering with the monetary base, which could be the case under a currency or a deposit
} 
In conclusion, and since at the time of writing the debate on national accounts' treatment of digital currencies remains inconclusive, we make the following two working assumptions in order to allocate CBDCs and stablecoins and their respective issuers within the system of financial accounts: ${ }^{12}$

- For a CBDC: Under the institutional sector of a central bank, a CBDC is a deposit instrument similar to existing central bank deposit facilities but with an extended list of counterparties, including nonfinancial agents.

- For stablecoins: Under the institutional sector of non-money market fund investment funds, stablecoin is either (i) a new instrument listed as "non-MFI deposits" or (ii) an investment fund share in the context of a collective investment scheme. In addition, for stablecoins, both domestic and foreign initiatives will be considered. In the case of the latter, the institutional sector hosting the stablecoin will be the "rest of the world" sector, but we assume that there will be a local domestic subsidiary (possibly due to a regulatory requirement) in the domestic investment funds sector.

Finally, it is of course entirely possible that stablecoins will be classified as credit institutions or deposit taking institutions, or as electronic money institutions, in which case the relevant instrument category could be deposits, as is the case for commercial banks today. Additionally, if the stablecoin reserve fund were to strictly invest only in deposit-like assets (either commercial bank sight deposits or short-term government securities), the scheme could be classified as a money market fund. In all these cases, the institutional sector would be the $\mathrm{MFI}$, and the introduction of a stablecoin would, in the first round, involve internal shifts within the MFI sector only. Illustrating such moves in a financial accounts network would require who-to-whom data for the MFI subsectors, which are currently unavailable in the Euro Area Accounts.

scheme. They also argue that the risk of bank disintermediation would then be mitigated, owing to the UCIT/ETF legal structure, which prevents them from engaging in lending activities.

${ }^{12}$ Once again, owing to the large number of different digital asset designs, the full range of classifications as listed above may be entirely appropriate for the case-by-case assessment of the statistical and regulatory allocation of a specific asset. 


\section{Introducing Digital Currency in Macro Networks}

\subsection{The Macro Network}

Following Castrén and Kavonius (2013) and Castrén and Rancan (2014), we model the EAA data, introduced in Section 2, as a macro-network. The macro-network consists of a set of bilateral links between the main institutional sectors which constitute the nodes of the network. The links are the EAA who-to-whom statistics for the different financial instruments. Separate macro-networks are drawn for the different financial instruments. The macro-network allows us to model the financial system as an intertwined set of agents that is particularly suitable to account for shock propagation and feedback effects. ${ }^{13}$

Figure 1 shows the status quo macro-networks of two separate instrument categories, deposits (Panel A) and debt securities (Panel B). The directions of the links between the nodes (the sectors) show the direction of a claim (from liabilities to assets). In the case of deposits, the households (HH), the non-financial corporates (NFC) and the rest of the world (RoW) sectors hold deposit claims that are issued mostly by commercial banks (monetary financing institutions, MFIs). The network is incomplete and dominated by strong links between a small number of sectors. By contrast, the network of debt securities is much more complete, as the issuance and holdings of these instruments are more evenly distributed across the sectors. ${ }^{14}$

\footnotetext{
13 There is now an extensive body of literature on financial networks. In their study of bank runs, Allen and Gale (2000) demonstrated the different contagion effects implied by complete versus incomplete network structures. Several papers study contagion effects across financial institutions, using interbank loans as financial links (e.g., Upper and Worms, 2004; Gai and Kapadia, 2010; Mistrulli, 2011; Glasserman and Young, 2015). Some authors have considered a broader set of interlinkages between banks, both on the asset and the liability side, with the aim of better characterizing the way in which financial institutions are connected to each other (Aldasoro and Alves, 2018; Poledna et al., 2015; Bargigli et al., 2015; Caccioli et al., 2014). Papers that investigate network structures and their properties include Craig and von Peter (2014) and Peltonen et al. (2014). Departing from the micro-level analysis, some authors treat the network nodes as more aggregate entities, such as countries (see, e.g., Kali and Reyes, 2010) or industries (see, e.g., Acemoglu et al., 2016).

${ }^{14}$ Note that because the data from Euro Area Accounts are non-consolidated, they include intra-sector exposures. For the clarity of the presentation, the intra-sector links are not shown in the graphs, but they are always accounted for in the calculations.
} 
Figure 1: Examples of Macro Networks in Two Categories of Financial Instruments.
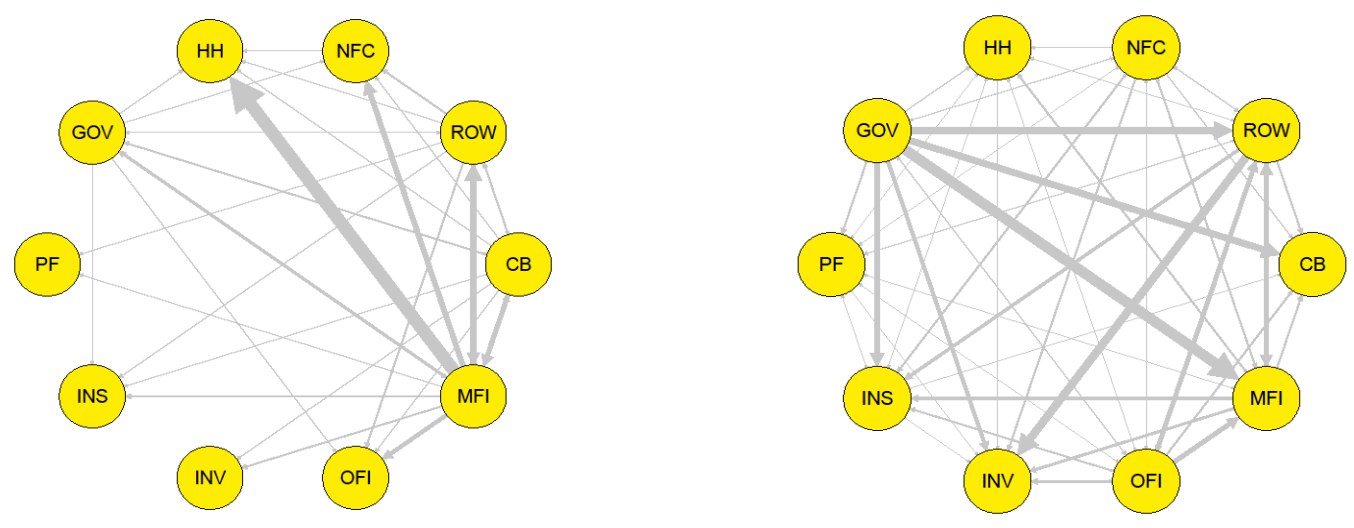

Arrows run from liabilities to assets.

\subsection{The Conceptual Framework}

A complete analytical presentation of the model can be found in the Annex to this paper. The presentation here instead follows a qualitative approach. The starting point of the analysis is the status quo macro-network for a given instrument category, calculated using the data as of Q1 2019. At time $t=0$, the digital currency is issued, depending on the particular design and institutional classification of the scheme, either by the central bank (CB), the investment funds sector (INV), or the rest of the world sector (RoW). As discussed in Section 3, for the issuing sector, the digital currency is a liability item classified either as a deposit or as an investment fund share, again depending on the specific characteristics of the digital currency. At time $t=1$, the introduction of the digital currency triggers a withdrawal of deposits by both households $(\mathrm{HH})$ and non-financial corporations (NFC) from domestic commercial banks (the MFI sector). We refer to this as step 1 and assume that the shock is identical in all scenarios below. In step 2, the funds withdrawn from the banks are placed with the sector hosting the digital currency. Finally, at time $t=2$, both the digital-currency-issuing sector and the banking sector must rebalance their accounts. ${ }^{15}$ This process will have implications for both the size of the bilateral links and the shape of the macro-network. Figure 2 provides a sketch of the effects that the introduction of the digital currency has, at each point in time, on the macro-network. The decisions to be taken at $\mathrm{t}=2$ by the various sectors are formalised in the Annex.

\footnotetext{
15 The process assumes that the affected sectors operate under certain target capital and/or leverage ratios and that they pursue some specific instrument mix both for their assets and liabilities. Alternatively, the sectors could absorb the shock in their capital or net wealth positions and restore capital by issuing equity or retaining earnings over time. However, we do not consider these possibilities here.
} 
Figure 2: Timeline of the Introduction of the Digital Currency in the Macro-Network.

\begin{tabular}{|c|c|c|}
\hline $\begin{array}{l}\text { Issuance of Digital } \\
\quad \text { Currency } \\
\text { The digital currency is issued } \\
\text { by: } \\
\text { - CB, } \\
\text { - INV, or } \\
\text { - RoW } \\
\text { Digital currency is classified } \\
\text { either as a deposit or a } \\
\text { collective investment } \\
\text { scheme }\end{array}$ & $\begin{array}{l}\text { Shock realizes } \\
\text { Step 1: HH and NFC } \\
\text { withdrawn part of their } \\
\text { deposits from MFI } \\
\text { Step 2: HH and NFC } \\
\text { deposit money in the } \\
\text { sector issuing the } \\
\text { digital currency }\end{array}$ & $\begin{array}{l}\text { Sector issuing digital currency } \\
\text { and MFI rebalance their } \\
\text { portfolios triggering further } \\
\text { adjustments in the economy } \\
\text { Sector issuing the digital currency } \\
\text { may: } \\
\text { i) redeposit the funds to the MFI; } \\
\text { ii) invest in debt securities. } \\
\text { MFI may: } \\
\text { i) rely on the funds re-deposited by } \\
\text { the sector issuing the digital } \\
\text { currency; } \\
\text { ii) Sell debt securities (assets); } \\
\text { iii) Redeem loans (assets); } \\
\text { iv) Issue debt securities (liabilities). } \\
\text { These behavioral responses trigger } \\
\text { further adjustments in the system. }\end{array}$ \\
\hline
\end{tabular}

It is important to stress that the changes in the bilateral exposures described here may be short-lived if the digital currency serves only as a means of payment (a payment instrument that facilitates transactions between agents, possibly cross-border). In that case, after the payment transaction has been completed, the agents in the $\mathrm{HH}$ and/or the NFC sectors convert their digital currency back into commercial bank deposits, or cash. If, by contrast, the digital currency also serves as a store of value, then the shifts in exposures may become permanent. For the simulations presented below, the duration of the shifts plays no role, but this does not mean that the persistence of the moves is economically meaningless. On the one hand, large and frequent but short-lasting shifts in and out of retail deposits would add to the volatility of bank funding sources. This would tend to increase banks' funding costs and elevate the risk of breaches of key liquidity measures, inducing the banks to hold additional liquidity buffers and possibly making them more wary of committing to long-term lending and investment decisions. On the other hand, permanent shifts out of commercial bank deposits could lead to disintermediation of the banking sector, with important consequences for banks' asset holdings, their pricing of loans and debt securities, and the general bank lending conditions. In an extreme scenario highlighted by Juks (2018), Kumhof and Moore (2018) and Bindseil (2020), the introduction of a digital currency could trigger a run on retail bank deposits, with severe consequences for the stability of the system and the financing of the non-financial sectors. 


\section{Scenario Analysis}

Following the detailed discussion in Section 3, we begin with cases where the digital currency - either a public or a private initiative - is classified as a deposit scheme. We then present the case of a collective investment scheme for a private initiative (stablecoin). In all scenarios, the initial shock is a withdrawal of $20 \%$ of the stock of MFI deposits by both households and firms. Below in section 6 we will consider a wider range of shocks.

\subsection{Digital Currency as a Deposit Scheme}

In the case of a deposit scheme, at $t=1$ all changes in the bilateral exposures occur in the network of deposits. We consider three separate options for the institutional classification of the digital currency. In option one, the digital currency issuer is the central bank. In option two, the digital currency issuer is a private entity, operating as part of the investment funds sector (INV). In option three, the issuer is a foreign stablecoin located in the "rest of the world" sector (RoW) but with part of its global reserve fund assets denominated in the domestic currency. The vehicle controlling the domestic fraction of the reserve fund is a locally licenced and supervised subsidiary within the domestic investment funds (INV) sector.

\subsubsection{Central Bank Digital Currency (CBDC)}

Consider first the case of a CBDC. Figure 3 illustrates the impact of the introduction of the CBDC at $t=1$, step-bystep. Panel A depicts the network of deposits before the introduction of the CBDC (the status quo situation). In Panel B, private non-financial-sector depositors have withdrawn $20 \%$ of their commercial bank (MFI) deposits (the light blue arrows show the "weakened" deposit links after the withdrawals). In Panel C, the deposits withdrawn from the commercial banks have been placed in accounts with the central bank (the dark blue arrows), so that households and firms now hold direct claims against the central bank. 
Figure 3: Network of Institutional Sectors, Instrument Deposits, $t=1$.

Panel A: Network of Deposits, Status Quo

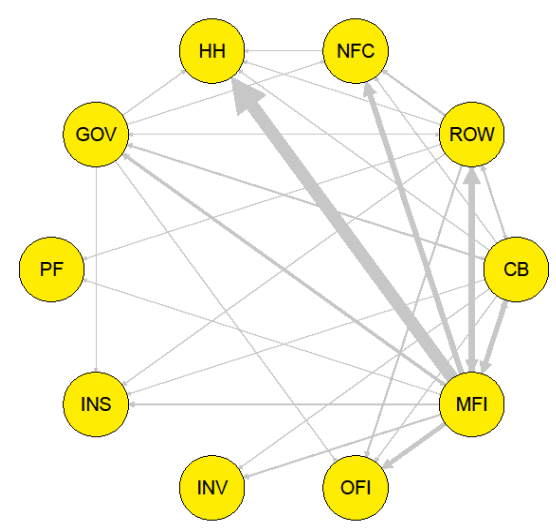

Panel B: Network of Deposits after NFC and HH Have withdrawn Funds from MFI

Panel C: Network of Deposits after Funds Have Been Moved to CBDC

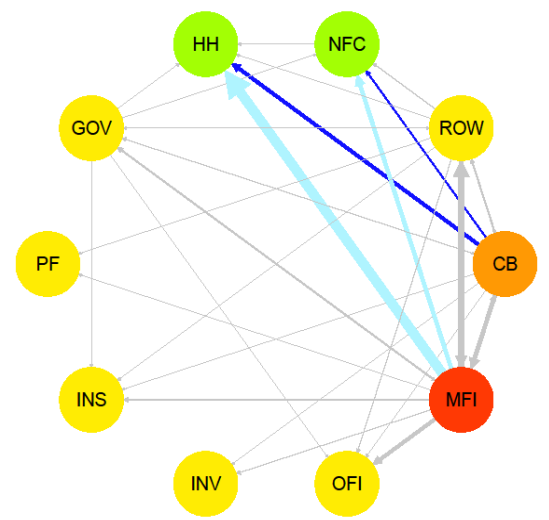

Arrows run from liabilities to assets.

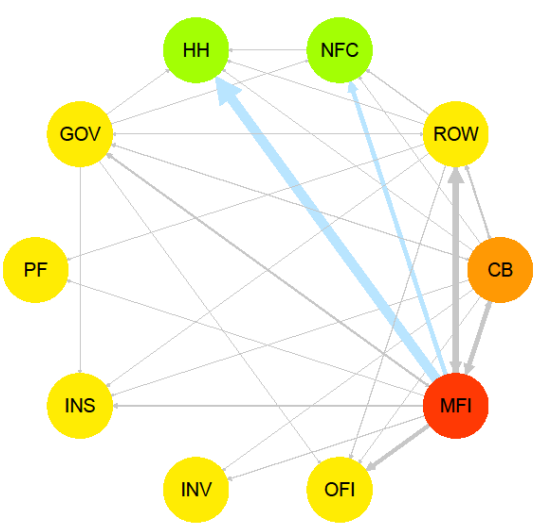


As explained in general terms in Section 4.2, the shifts in deposits trigger wider changes in the affected sectors' balance sheet aggregates at $t=2$. We consider a non-exhaustive list of four alternative scenarios - each of which describe a set of actions independently taken by the relevant agents - that are sufficient to complete the process.

A) The CB redeposits the funds with the commercial banks (MFIs) to offset the increase in its deposit liabilities;

B) The MFI sells debt securities (assets) to offset the reduction in its deposit liabilities; the CB purchases debt securities to offset the increase in its deposit liabilities;

C) The MFI redeems loans (assets) to offset the reduction in its deposit liabilities; the sector which loses bank financing replaces loans by issuing its own debt securities; the CB purchases debt securities to offset the increase in its deposit liabilities;

D) The MFI issues debt securities (liabilities) to offset the reduction in its deposit liabilities; the CB purchases debt securities to offset the increase in its deposit liabilities.

As a result of all these transactions, the central bank's balance sheet expands while the commercial banks' balance sheet either shrinks (in cases B and C) or remains unchanged (in cases A and D). This does not necessarily have to be the case, however. The central bank could also decide to offset the increase in its liabilities by using the CBDC as a substitute for other liability items, for example by retiring banknotes.

Importantly, while in cases B to D the commercial banks either sell securities from their portfolios or issue securities as new liabilities, and the central bank simultaneously purchases securities, the sales and purchases are made independently and do not necessarily match in terms of their composition. This is because the securities holdings (portfolios) of each sector are different, and therefore the preferred sets of securities to be purchased and sold are not the same. We return to this point shortly.

Figure 4 shows case $A$. The re-depositing of the funds by the CB to the commercial banks (MFIs) is shown by the blue arrow. In practice, the transaction is a monetary policy operation whereby the banks tap the central bank repo financing facility to cover their funding gaps. Although, in terms of balance sheet items, the loans from the central bank fully offset the banks' funding gaps, there are other characteristics that make the positions heterogeneous. First, in terms of pricing, the banks' funding has now shifted from cheaper retail deposits to more expensive central bank repos. Second, central bank repo financing is collateralised, which means that a relevant share of the banks' securities portfolios will become encumbered. Third, central bank financing is shortterm and has to be rolled in the absence of alternative funding sources. By contrast, retail deposits, although in theory mostly callable on demand, are in practice the most stable source of bank funding (Gropp and Heider, 2010). 
Figure 4: Network of Institutional Sectors, Instrument Deposits, t=2, Case A. Network of deposits after CB redeposits funds at $\mathrm{MFI}$.

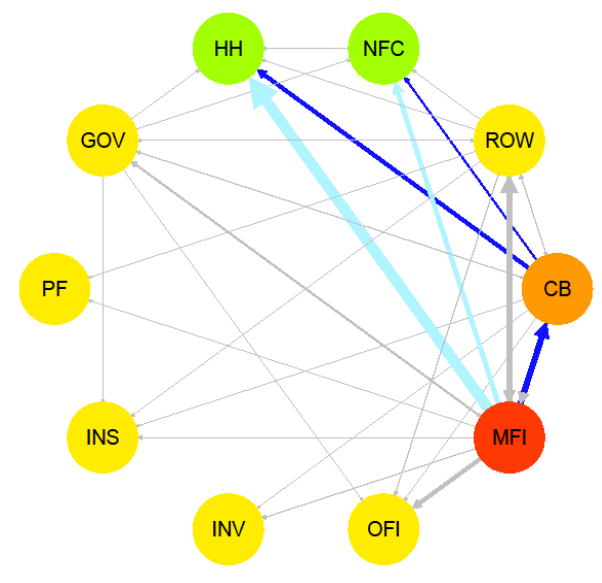

Arrows run from liabilities to assets.

Figure 5, in turn, shows case B, where the rebalancing occurs via the actions of the commercial banks. Note that since the process involves transactions in debt securities rather than deposits, the macro-network considered in this case is drawn in the former instrument category. Panel A illustrates the status quo network, where for debt securities in the euro area the main issuing sectors are the government and the RoW. The main holding sectors are the investment funds (INV), MFIs (banks) and, as a result of the Eurosystem's extensive QE policies, the central bank.

Panel B shows the network of debt securities after the commercial banks have sold bonds from their investment portfolios. Given that the banks' securities portfolios consist of bonds issued by several other sectors, including the MFI itself, it is necessary to introduce some order according to which the different types of bonds will be sold. In the simulations below, the banks are assumed to dispose of debt securities in proportion to their existing holdings, in order to cause minimum changes to their existing portfolio structures. However, one could easily imagine alternative strategies. For example, the order in which the bonds are sold could instead be stipulated by their risk characteristics. In this case, the bonds with the lowest ratings and/or the highest risk weights (such as high-yield corporate bonds) would be offloaded first, whereas the bonds with the lowest risk weights (those issued by the government sector, with zero risk weight) would be the last ones to be sold. Another strategy would be to sell the most liquid bonds first, an approach that would typically be deployed in emergency, or firesale, situations. In this case government bonds and credit issued by larger, higher rated corporates would be at the top of the sales list.

In Panel C, the central bank uses the resources it receives from the introduction of the CBDC to increase its holdings of debt securities. However, here the central bank also purchases bonds in proportion to its existing holdings. An alternative strategy would be akin to QE purchases, where acquisitions are made according to a pre-announced plan for different types of bonds; it is not unreasonable to assume that CBDC-related purchases would also follow some plan that the central bank could decide to make public. 
Overall, the differences in portfolio structures and rebalancing strategies across the sectors mean that in the rebalancing process the bonds that are subject to bids and those that are offered are not the same. The heterogeneous compositions of the commercial banks' and central bank's bond portfolios mean that some bonds will be subject to excess demand, while an excess of supply will occur for others, and market clearing will consequently require price adjustments. Panel $D$ illustrates the resulting imbalance between the supply of and demand for bonds, by the issuing sector. In the cases where supply from the commercial banks (the red bars) exceeds the demand from the central bank (the blue bars), the bond prices will fall, and vice versa in the cases where demand exceeds supply. Under the rules invoked in this stylised exercise, the bonds facing downward price pressure are those issued by the RoW sector. Conversely, the bonds facing upward price pressure are those issued by GOV and, to a lesser extent, the MFI, OFI and INS sectors. Commercial banks are large holders of foreign debt instruments, while the CB usually refrains from such purchases in operations other than dedicated foreign exchange interventions. In our example, the excess supply of foreign bonds is likely to contribute both to a fall in their price and to a depreciation of the foreign currency vis-à-vis the domestic currency. 
Figure 5: Network of Institutional Sectors, Instrument Debt Securities, $t=2$, case B.
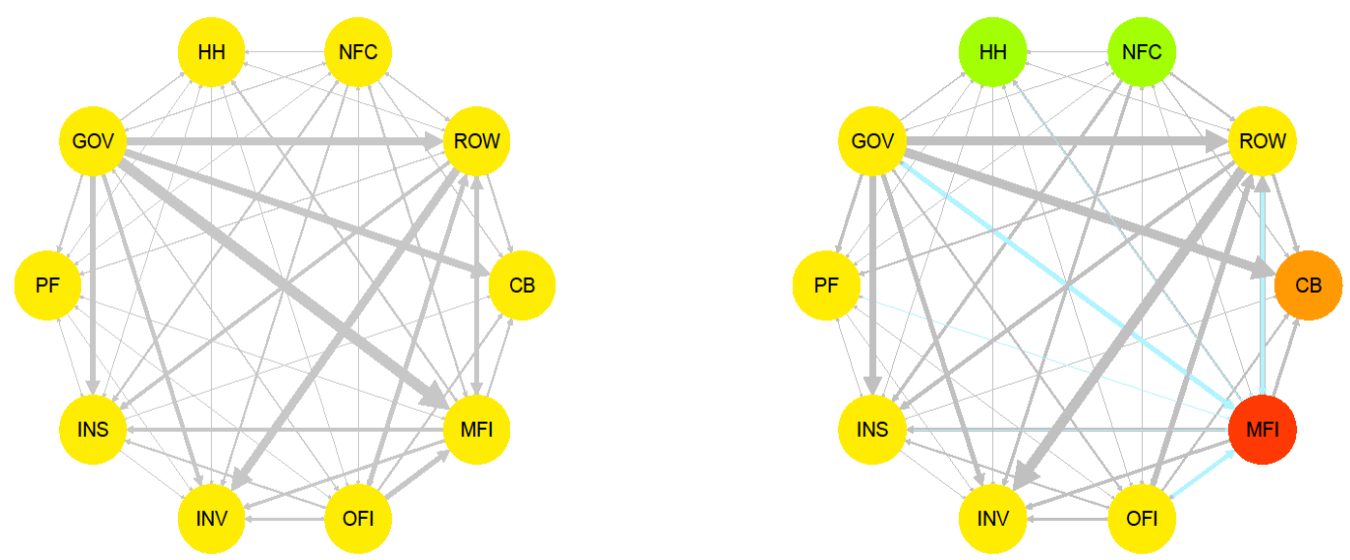

Panel C: Network of Debt Securities, after CB Has Increased Holdings Proportionally

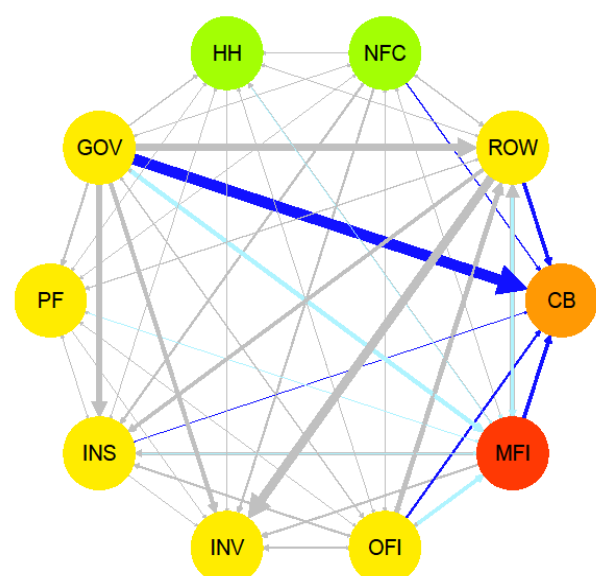

Panel D: Differences Between MFI Sales and CB Purchases of Debt Securities, by Issuing Sector

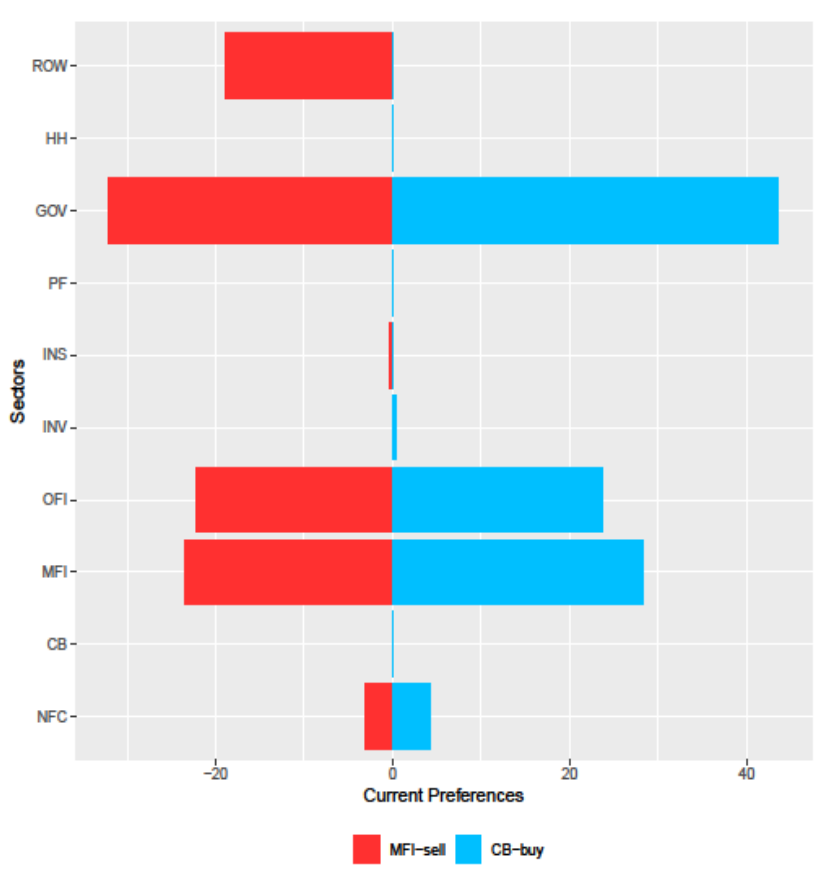

Arrows run from liabilities to assets. 
Figure 6 shows Case C, where the commercial banks redeem loans to offset the loss of deposits. Panel A shows the status quo network of loans, where the MFI, RoW and OFI sectors are the key nodes. The baseline assumption in such a "deleveraging scenario" is again that loans are redeemed proportionally, based on the current stock of loans extended by the banks to the other sectors (including interbank lending within the MFI sector itself). However, also in this case, plausible alternative scenarios can be envisaged, for example redemption decisions could be based on the risk characteristics of the loans. In that case, consumer credit and corporate SME loans would typically be redeemed first, owing to their higher historical loss characteristics. Panel $B$ shows the network of loans after proportional redemptions by the MFI. The sectors that are most affected are $\mathrm{HH}$ and NFC, which are the largest borrowers from the banks in the euro area financial system, followed by the GOV and RoW sectors.

The borrowing sectors that lose part of their bank funding now face the choice of either shedding assets or seeking alternative funding sources. The latter can be either new loans extended by some other sector, or debt securities issued by the sector itself. We assume that the sectors with access to debt capital markets - mainly the Government, NFC and RoW sectors - choose to issue new bonds, while the households sector reduces its existing bond holdings (assets) to offset the loss of bank financing.

Panel $\mathrm{C}$ shows the supply-demand imbalances that arise in this case. Note that the demand side for debt securities is similar to that in Figure 5, Panel D, because the central bank again rebalances its portfolio proportionally, given its existing mix of bond holdings. However, on the supply side, there are now both the debt securities sold by $\mathrm{HH}$, which are bonds issued mainly by the GOV and MFI sectors, and the debt securities newly issued by mostly the NFC, OFI, RoW and GOV sectors. Combining the behavioural responses of all sectors, the bonds now facing most downward price pressure are those issued by the firms sector (NFC), while the bonds experiencing upward price pressure are those issued by GOV, MFI, and OFI. The significant deterioration of the non-financial corporate sector funding situation in this case comes from two distinct sources. First, firms in the euro area rely heavily on bank loans as a funding source, and they are therefore strongly affected by the deleveraging of the commercial banks in stage 1. Second, according to its portfolio structure, the central bank purchases only a relatively small portion of the non-financial corporate bonds that the firms issue in stage 2 to substitute for the reduced lending by the commercial banks. 
Figure 6: Network of Institutional Sectors, Instrument Loans, $t=2$, case C.
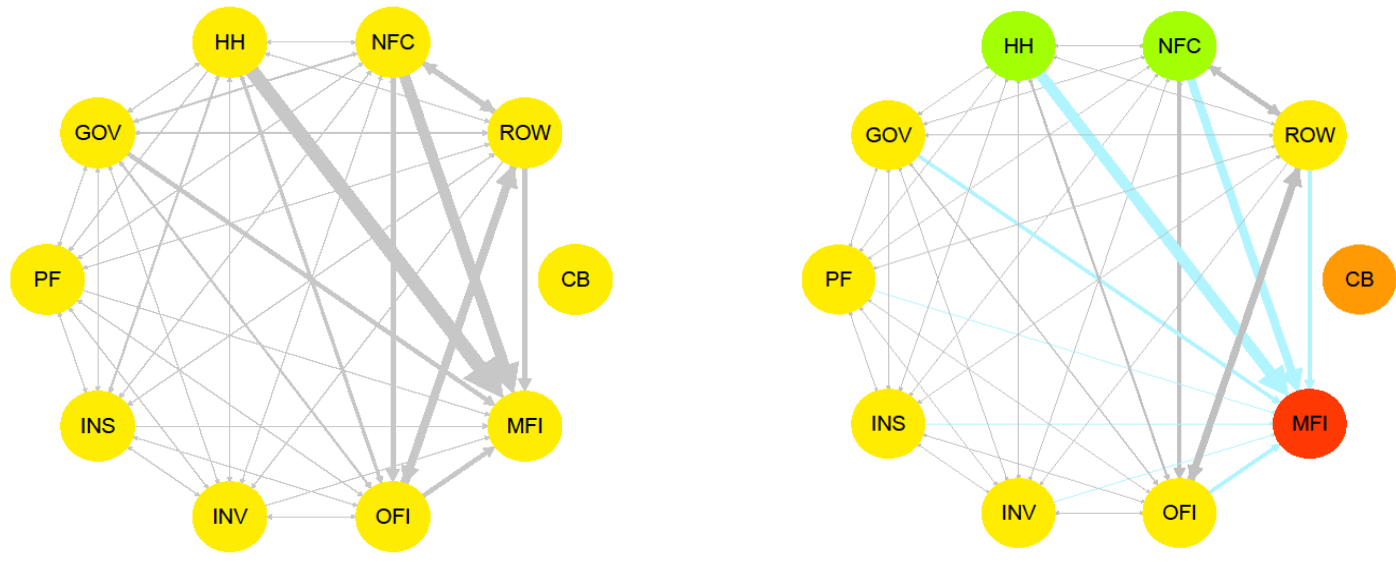

Panel C: Differences Between Sales/Issuance and CB

Purchases of Debt Securities, by Issuing Sector

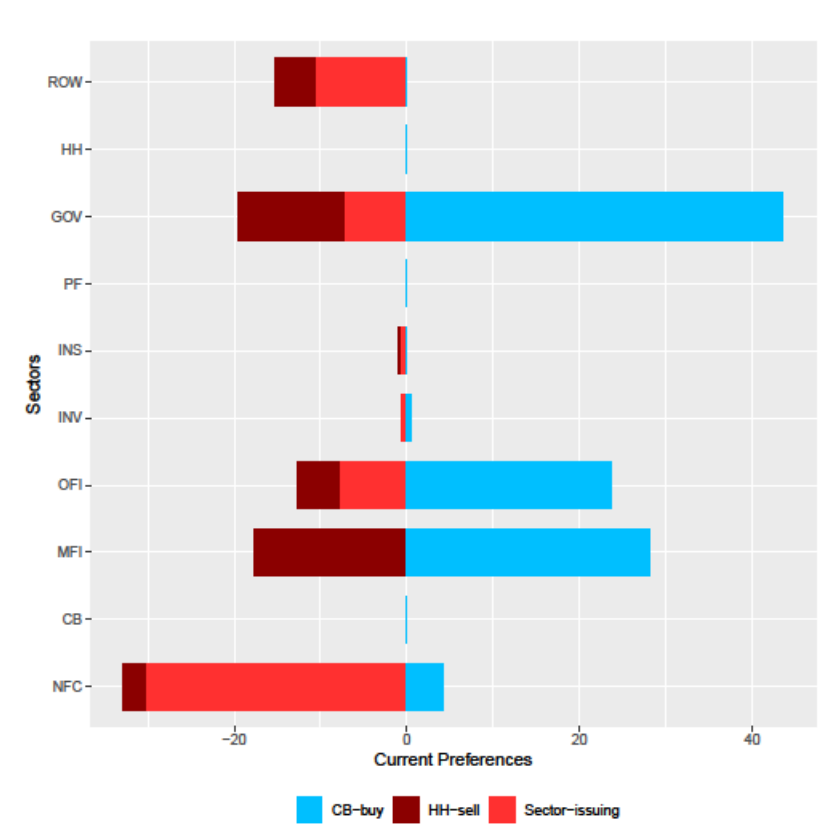

Arrows run from liabilities to assets. 
Finally, Figure 7 demonstrates Case $D$, where rebalancing takes the form of the commercial banks issuing new bonds (Panel B) and the CB increasing its bond holdings (Panel C). Because the entire supply of debt securities now consists of bank bonds, while the demand side is again split across various issuers according to the CB's current portfolio, market clearing requires a meaningful drop in the price of MFI bonds (Panel D). According to the baseline rule of proportional purchases, the CB would absorb only around $12 \%$ of the newly issued bank bonds, while, based on its current portfolio structure, it would have the strongest demand for government bonds (65\%). ${ }^{16}$ In this scenario, the commercial banks therefore not only lose deposits to the CBDC in stage 1 but they also see an increase in their cost of market-based funding in stage 2, due to the limited capacity of the other sectors to absorb new MFI issuance. ${ }^{17}$

\footnotetext{
${ }^{16}$ In the case of the Eurosystem, the cumulative purchases made under the Asset Purchase Programme (APP) have skewed the Eurosystem's securities portfolio heavily in favour of government bonds. In addition, as regards MFI bonds, the Eurosystem rules currently allow purchases of covered bonds only. Other sectors, including the RoW, insurance companies, pension funds, investment funds and households, are the largest buyers of unsecured MFI bonds.

${ }^{17}$ The drop in bank bond prices that is necessary for the markets to clear implies an increase in yield, thus adding to the periodic coupon payments both on new debt and on the outstanding stock of debt.
} 
Figure 7: Network of Institutional Sectors, Instrument Category Debt Securities, $t=2$, case D.

Panel A: Network of Debt Securities, Status Quo
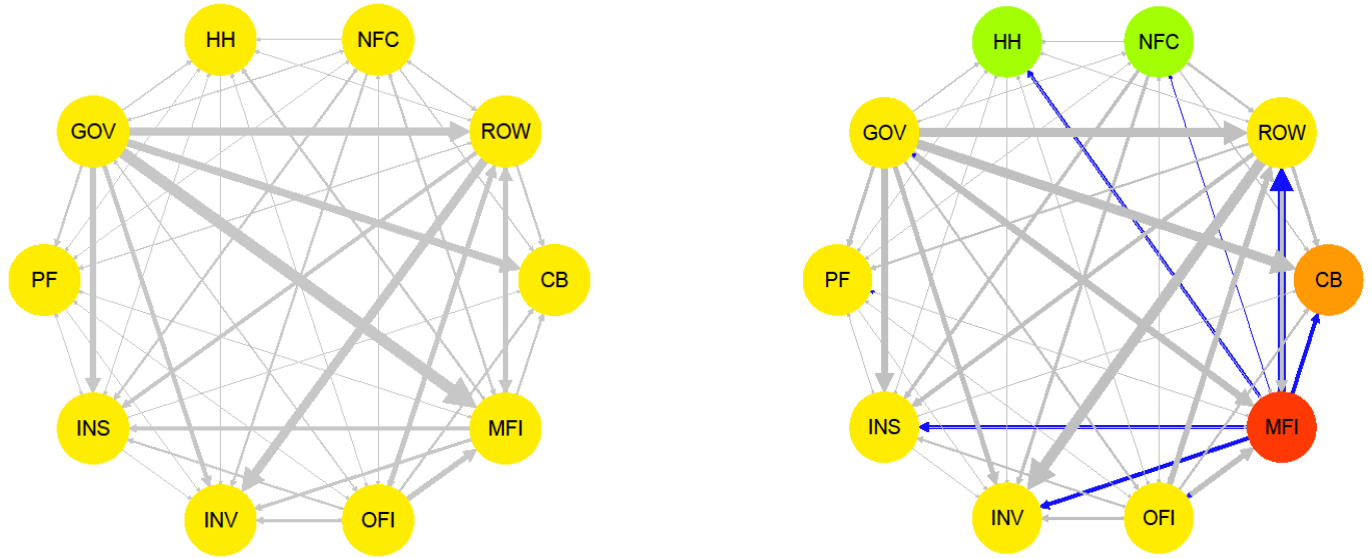

Panel C: Network of Debt Securities, after CB Increased Holdings Proportionally

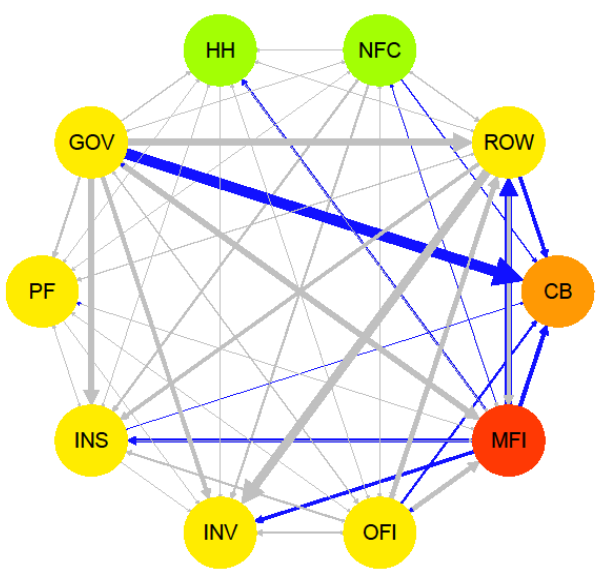

Panel D: Differences Between MFI Issuance and CB Purchases of Debt Securities, by Issuing Sector

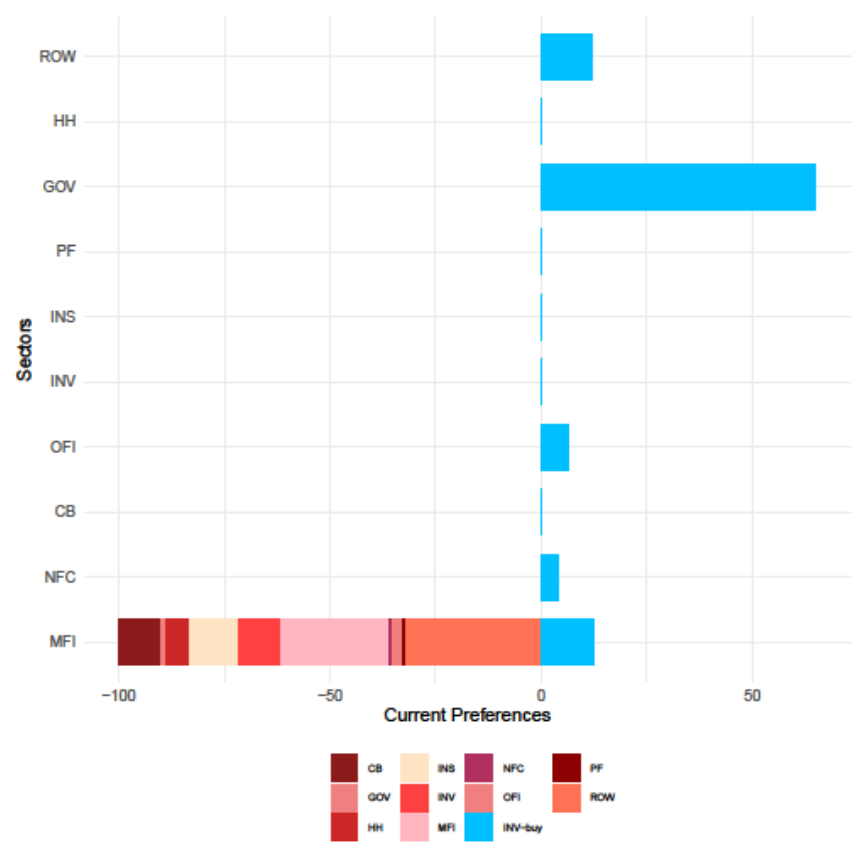

Arrows run from liabilities to assets. 
In discussing the potential risks of introducing a CBDC, Bindseil (2020) and Kumhof and Noone (2018) focus on the possibility of deposit runs in commercial banks and, to a lesser extent, the risk of disintermediation of the banks' lending activities. These prospects are also evident in our analysis if we scale up the size of the deposit shock. ${ }^{18}$ However, our network approach allows us to unearth another vulnerability, which is the asymmetric price adjustment in marketable securities triggered by the rebalancing process.

To minimise these distortions, the central bank has several options, each of which seem to represent a secondbest solution compared to the current system (but other perceived benefits from a CBDC may of course outweigh these losses). First, the central bank may lend the funds to the commercial banks, with the result, however, that this part of the banks' funding becomes collateralised, short-term and more expensive. Second, the CB could adjust its securities purchases to match as closely as possible the set of securities offered by the commercial banks (or by the sectors affected by the deleveraging of the commercial banks). In practice, this would mean increasing CB purchases of bonds issued by the private sector (especially MFI and NFC) and the rest of the world, which may prove politically controversial for the CB. Third, the CB could set up a loan portfolio for non-financial sectors with the aim of covering those borrowers most affected by the commercial banks' deleveraging. A legitimate question is whether the public sector possesses the skills and the information to price and risk-manage loans in a way that achieves a more efficient allocation of credit to the private sector than is the case under the current allocation by the commercial banks.

\subsubsection{A Domestic Stablecoin Initiative}

Now consider the case where the digital currency is a stablecoin issued by a private domestic entity rather than the central bank. Such initiatives have been launched globally mainly as domestic payment projects that operate under a single jurisdiction or a single currency area. ${ }^{19}$ As discussed in Section 3, in our framework the stablecoin issuer is incorporated into the investment funds sector (INV). In Figure 8, the deposits that shift out of the commercial banks (the MFI sector, Panel B) are now directed to the investment funds sector as "non-MFI deposits" (Panel C).

\footnotetext{
${ }^{18}$ We look at this possibility in detail in Section 6.

${ }^{19}$ These projects range from small local payment operators to vast and near-dominant players in digital payments, such as AliPay and WeChat in China. The natural advantage with tech companies in this area is their ability to combine a proprietary payments rail with existing online platforms which provide large user bases and the potential for significant network effects.
} 
Figure 8: Network of Institutional Sectors, Instrument Deposits, $t=1$.
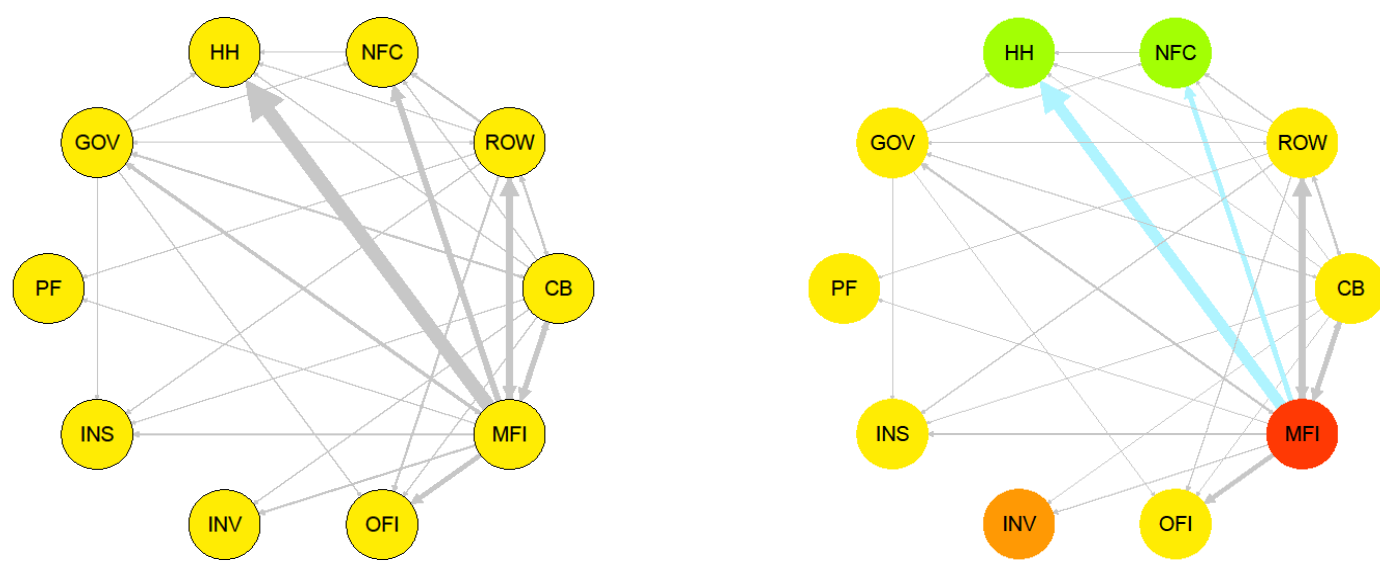

Panel C: Network of Deposits, after the Funds Have Moved to Stablecoin (INV Sector)

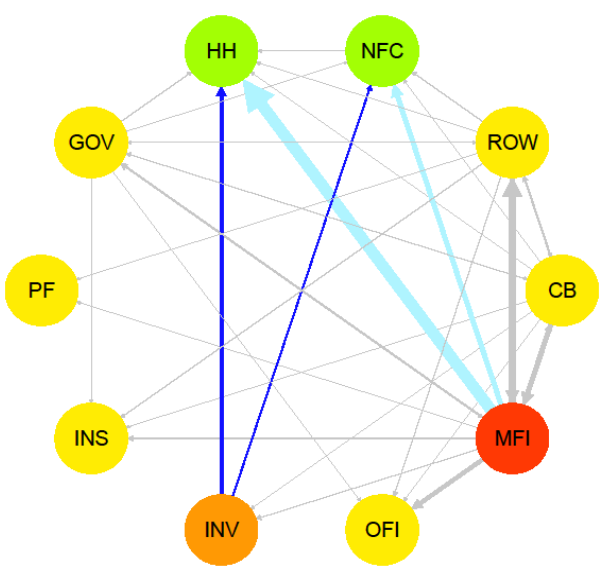

Arrows run from liabilities to assets. 
At $t=2$, the deposit shift again triggers a rebalancing process. We consider four alternative scenarios:

A) The stablecoin issuer (INV sector) redeposits the funds with the MFI sector and places the deposits in its reserve fund (assets) to offset the increase in its deposit liabilities

B) The MFI sells debt securities (assets) to offset the reduction in its deposit liabilities; the stablecoin (INV) purchases debt securities and places them in its reserve fund to offset the increase in its deposit liabilities

C) The MFI redeems loans (assets) to offset the reduction in its deposit liabilities; the sectors which lose bank financing replace bank loans by issuing new debt securities; the stablecoin (INV) purchases debt securities and places them in its reserve fund to offset the increase in its deposit liabilities

D) The MFI issues debt securities (liabilities) to offset the reduction in its deposit liabilities; the stablecoin (INV) purchases debt securities and places them in its reserve fund to offset the increase in its deposit liabilities

Case A is captured by Figure 9. The domestic stablecoin, which is part of the INV sector, redeposits the funds with the commercial banks (the MFI sector), as shown by the dark blue arrow now connecting the two sectors. The stablecoin reserve fund then consists of $100 \%$ commercial-bank deposits, and the rebalancing occurs without any action required by the MFI sector. As a result, the INV sector becomes a key node in the network of deposits.

Figure 9: Network of Institutional Sectors, Instrument Debt Securities, $t=2$, case A.

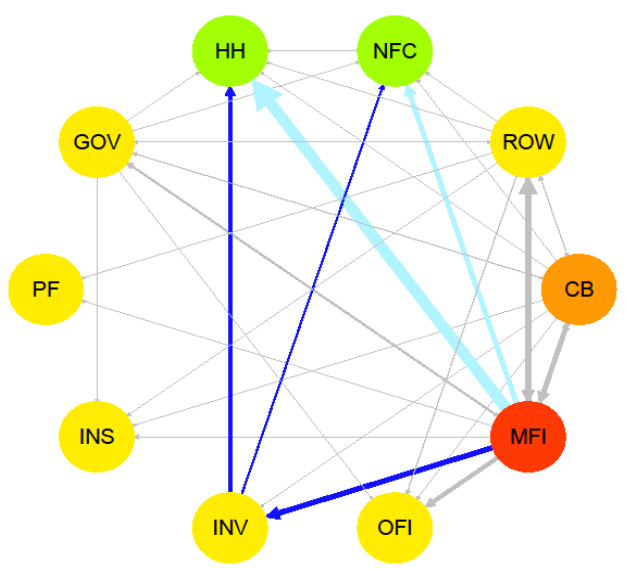

Arrows run from liabilities to assets. 
The re-depositing of funds by the stablecoin with the commercial banks raises some questions, however. For example, there is a priori no way of guaranteeing that the banks that lost deposits at $t=1$ are the same that will receive deposits from the stablecoin at $t=2$, unless the allocation is made according to some kind of competitive bidding process. Another option is to route the process via the central bank, which offers these deposits in its tender operations according to demand by individual banks.

In the cases where rebalancing takes the form of actions initiated by the commercial banks (the MFI sector) instead, the behavioural responses are similar to those in the case of the CBDC (see scenarios B-D Section 5.1.1). However, since the ultimate buyer of the debt securities is now the stablecoin (the INV sector), the purchases are made in proportion to its existing portfolio. Moreover, in this case, alternative rules could be considered. For example, the stablecoin issuer may want a reserve fund consisting of only cash-like securities, making the structure akin to a money market fund.

Figure 10 shows the results of scenarios B-D. Considering Case B, Panel A shows how the network of debt securities changes when the stablecoin (INV sector) rebalances its reserve fund by purchasing bonds in proportion to the fund's existing holdings. Panel B shows the resulting supply/demand imbalances in the bond market. The prices of GOV, OFI and MFI debt securities will face downward pressure, while the prices of RoW and NFC debt securities will experience upward pressure. ${ }^{20}$ Case C is displayed in Panel C. As in Error! Reference source not found., after commercial banks have reduced lending proportionate to their loan portfolios, the rebalancing involves, on the supply side, both the $\mathrm{HH}$ sector selling debt securities and the other sectors issuing new bonds. Downward price adjustments will now be prevalent for the NFC, MFI and OFI debt securities, while upward adjustments are limited to foreign (RoW) issued bonds.

In scenario D, the graph in Panel D shows the network of debt securities after the MFI sector has issued debt securities and the INV sector has increased its holdings proportionally. The shifts are illustrated by the dark blue arrows. Panel E shows how the bond issuance of the banking sector is only partly offset by the purchases of the stablecoin (the INV sector). The resulting excess supply of bank bonds will only be absorbed by the other sectors if prices fall. This drop in prices of MFI bonds would be more substantial if the stablecoin had a mandate only to purchase government issued securities.

\footnotetext{
${ }^{20}$ If the stablecoin reserve invested solely in cash-like assets, the GOV bonds would rise in price, whereas the prices of bonds issued by all other sectors would fall.
} 
Figure 10: Network of Institutional Sectors, Instrument Debt Securities, $t=2$, cases B, C and D.

\section{CASE B}

Panel A: Network of Debt Securities, after INV

Has Increased Holdings Proportionally

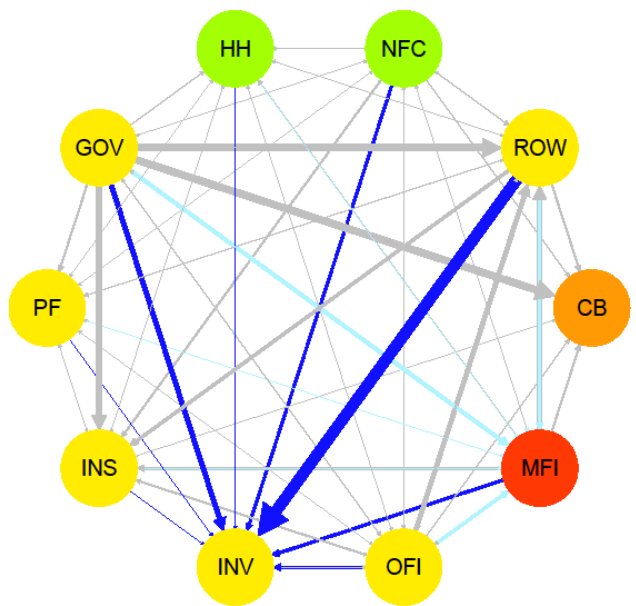

Panel B: Differences Between Supply and Demand of Debt Securities, by Issuing Sector

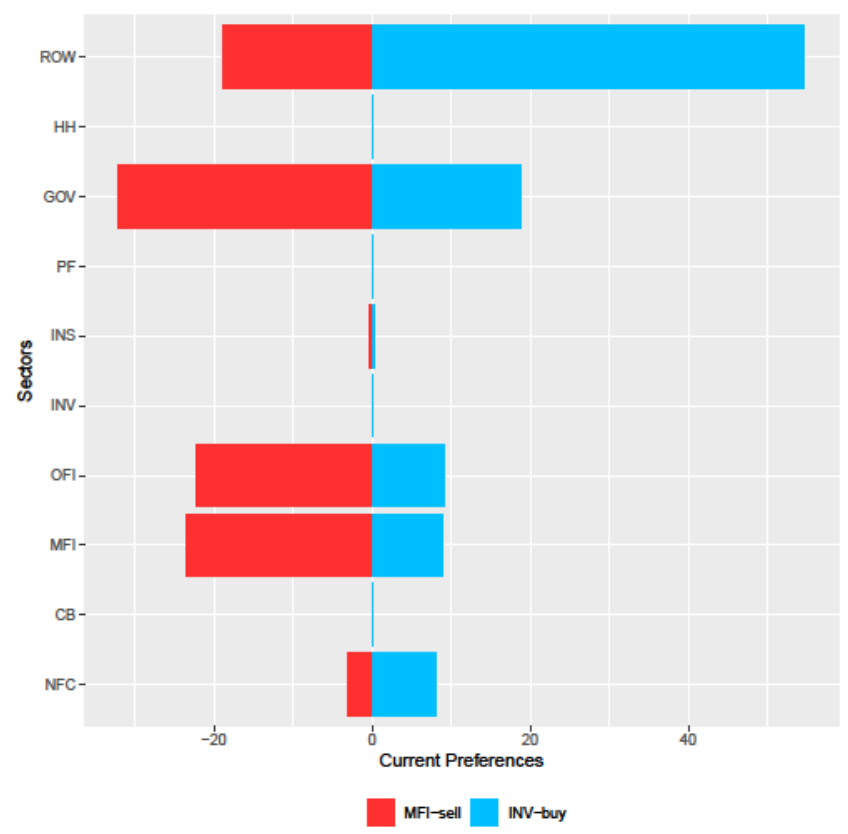




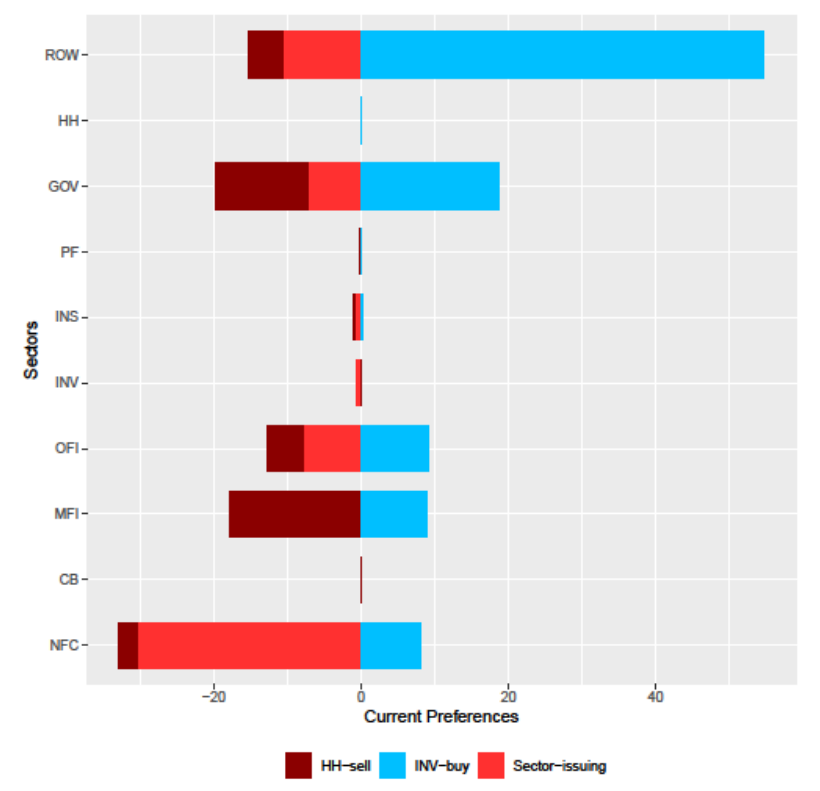

Case D

Panel D: Network of Debt Securities, after INV Has Increased Holdings Proportionally and MFI Has Issued Debt Securities

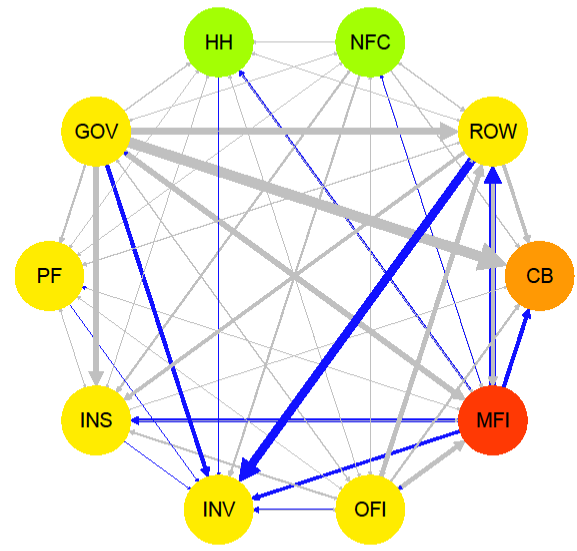

Panel E: Differences Between Supply and Demand of Debt Securities, by Issuing Sector

\section{Arrows run from liabilities to assets.}




\subsubsection{A Global Stablecoin Initiative}

The stablecoin can also be set up as a global initiative. The difference compared to the domestic model is that the RoW sector now plays a key role, with the relative importance of the domestic investment funds sector depending on the weight of the domestic economy in the stablecoin vehicle's global reserve fund. Some observers have suggested that a global stablecoin whose reserve fund is denominated in a (mix of) foreign currencies could be considered a currency board type arrangement (see Anderson and Papadia, 2020). For the analysis below, adopting this analogy would make no difference in theory but - following the discussion in Section 3 - since currency boards are not a concept that is included in either the national accounts or the regulatory classifications, we consider the initiative of a global private digital currency/stablecoin a non-MFI deposit scheme.

Figure 11 illustrates the case, with Panel A again showing the status quo network of deposits. Likewise, Panel B shows the network of deposits after $20 \%$ MFI deposit withdrawals by the HH and NFC sectors. In Panel C, the funds are transferred to the RoW sector where the stablecoin issuing vehicle now resides. Panel $D$ shows the final step under stage 1 , where the global stablecoin vehicle moves a share of $\gamma$ of its globally acquired deposits from the RoW (its home jurisdiction) back to the domestic financial system (the host jurisdiction from the global stablecoin's perspective), where $\gamma$ denotes the weight of the domestic currency (foreign currency from the global stablecoin's perspective) in the stablecoin's global reserve fund. In the simulations, it is assumed that this weight equals $30.93 \%$, which is the current weight of the EUR in the IMF's SDR basket. In our network of financial accounts, the domestic subsidiary of the global stablecoin is placed within the domestic Investment Funds sector (INV). 
Figure 11: Network of Institutional Sectors, Instrument Deposits, Stage I.

Panel A: Network of Deposits, Status Quo

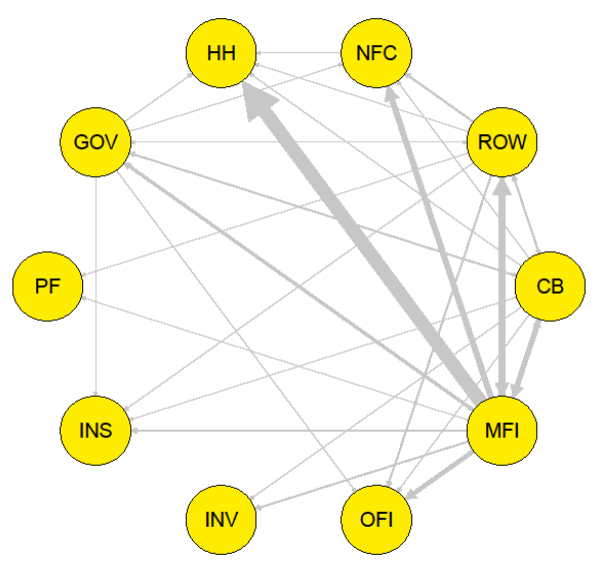

Panel B: Network of Deposits, After NFC and HH Have Withdrawn Deposits from MFI
Panel C: Network of Deposits, after Funds Have Shifted to Global Stablecoin in RoW

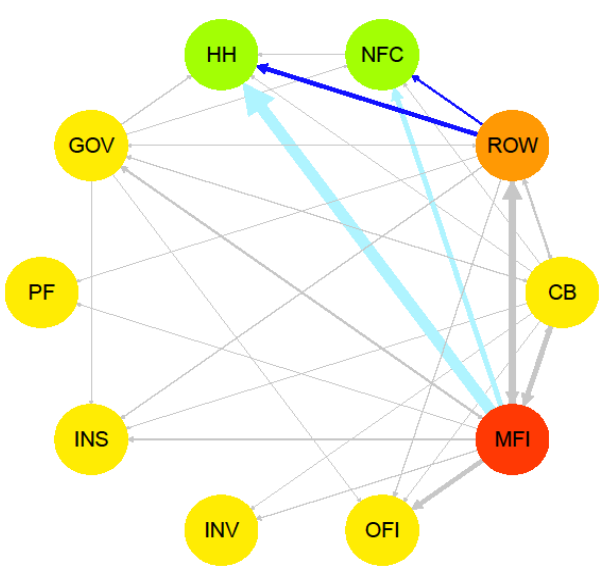

Panel D: Network of Deposits, after Global Stablecoin Has Re-Invested a Share $y$ in INV Sector

Arrows run from liabilities to assets.

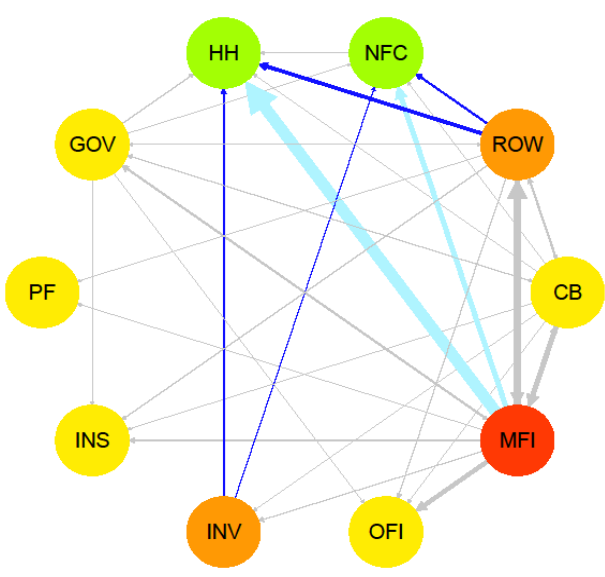


The rebalancing process must now take into account that the funds withdrawn from the commercial banks' deposit accounts are split between two sectors. The share of $\gamma$ will go to the global stablecoin's subsidiary in the home country (host country from the global stablecoin's perspective; placed in the INV sector), whereas the share of 1- $\gamma$ will permanently move to the RoW. The familiar options, A) to D), for rebalancing are now somewhat changed. Figure 12 shows option A), where the domestic INV sector first redeposits its share of $\gamma$ with the domestic commercial banks (the MFI sector), leaving the MFIs with a remaining funding gap of 1- $\gamma$ (Panel A). The RoW sector goes through its own internal rebalancing process, but at the end of the day, it will hold 1- $\gamma$ worth of surplus EUR denominated funds, which it will deposit in the home country CB (the Eurosystem). In the case of the Eurosystem, these funds would enter the balance sheet item "EUR denominated deposits by non-euro area residents" (Panel B). The domestic commercial banks then borrow these funds from the central bank in its repo operations to cover their remaining funding gap (Panel C).

Cases B-D are similar to those described in Sections 5.1 .1 and 5.1.2, with the difference being that if, for example, the MFI sector issues new bonds, these bonds cannot be purchased by the RoW sector, since the latter will not acquire euro area assets in excess of its share of 1-p. However, given that in a closed financial system the RoW sector ultimately redeposits its share of $1-\gamma$ with the domestic central bank, in cases B to $D$ the securities purchases are made jointly by the CB and the INV sectors, with the relative shares determined by the size of $\gamma$. 
Figure 12: Network of Institutional Sectors, Instrument Deposits, $t=2$, Case A.

Panel A: Network of Deposits, after INV Has Redeposited $\gamma$ with MFI

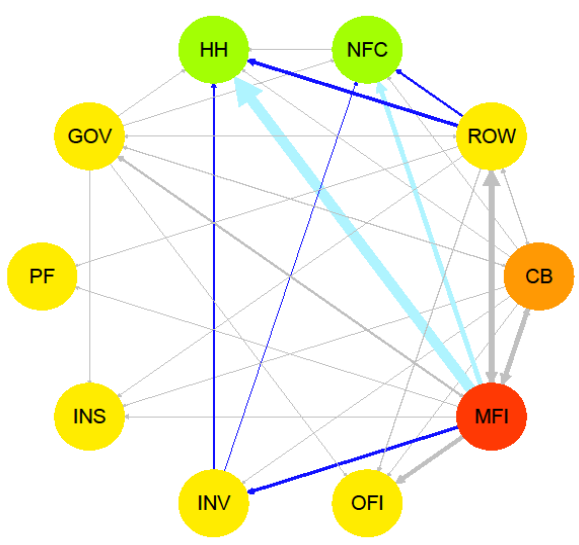

Panel B: Network of Deposits, after ROW Has Deposited $(1-\gamma)$ with the Domestic Central Bank

Panel C: Network of Deposits, after MFI Has Borrowed $(1-\gamma)$ from $C B$

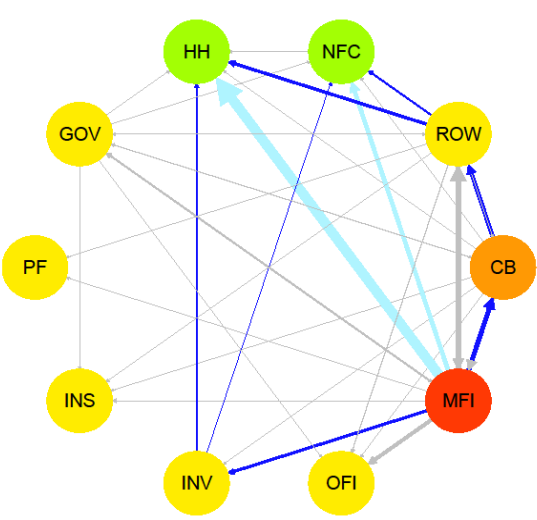

Arrows run from liabilities to assets. 


\subsection{Stablecoin as a Collective Investment Scheme}

Classifying a digital currency as a deposit scheme is only the simplest possibility, and, in the case of private initiatives, it may not even be the most plausible scenario. As discussed in Section 3, it might also be possible to consider private digital currencies/stablecoins as investment schemes, owing to the central role played by the stabilisation fund. For example, the proposed types of stablecoins could be compared to some existing investment fund structures, such as money market funds or exchange-traded funds (ETF). These fund types operate under broadly similar principles and have existing regulatory rules and practices associated with them.

Given that the proposed structure is not applicable to public initiatives such as a CBDC, the relevant institutional sector for the scheme is always the investment funds sector. The key difference compared to the case of a deposit scheme is that, as regards the instrument classification, the private digital currency now takes the form of investment fund shares issued against the stablecoin reserve that invests the deposits transferred from the banks. We again consider the domestic and global initiatives separately.

The starting point for the analysis is the same: the NFC and the HH sectors each withdraw $20 \%$ of their deposits from the commercial bank (MFI) accounts. In the case of the domestic stablecoin $\gamma=1$, and the domestic Investment Funds sector (INV) receives $100 \%$ of the funds. The stablecoin places the funds in its reserve fund and - being a collective investment scheme - issues the digital currency in the form of investment fund shares. Figure 13, Panel A shows the status quo network of investment fund shares where the RoW, HH, Insurance, and Pension Funds sectors are the major counterparty sectors to the INV sector. Panel B illustrates the network of investment fund shares after the funds withdrawn from the MFI deposits have been invested in the stablecoin. The $\mathrm{HH}$ and the NFC sectors now become key asset holding sectors in the macro-network of investment fund shares.

Figure 13: Network of Institutional Sectors, Instrument Investment Fund Shares, $t=1$.

Panel A: Network of Investment Funds Shares, Status Quo
Panel B: Network of Investment Funds Shares, after the HH and NFC Deposits Have Shifted to INV
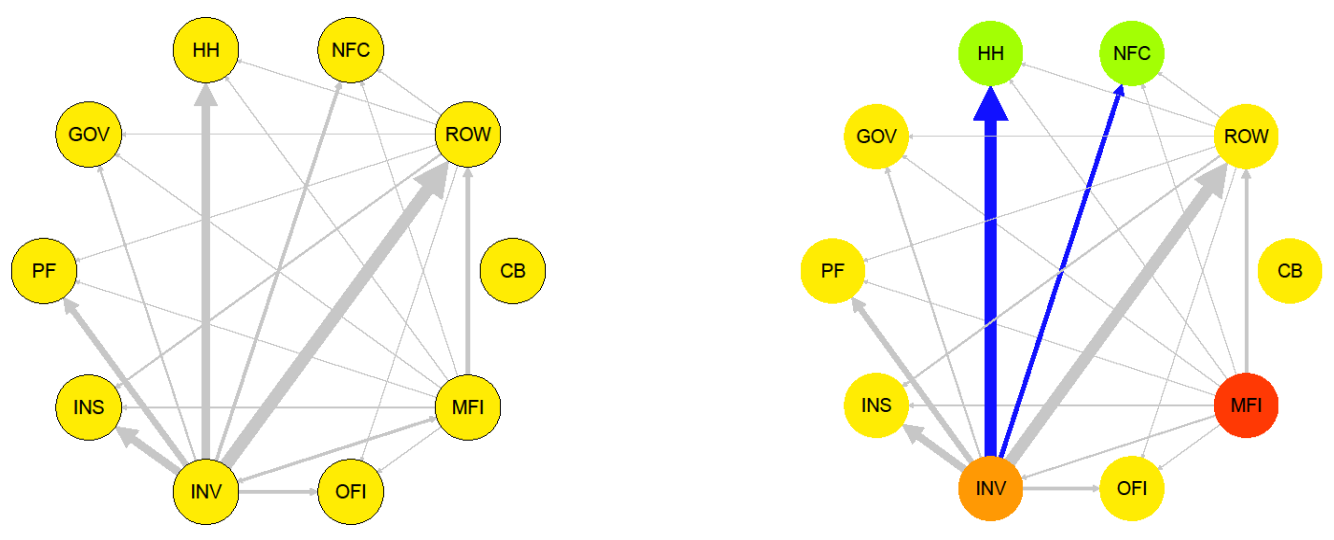

Arrows run from liabilities to assets. 
The case of the global stablecoin, where a fraction $y<1$ of the reserve funds is invested in the euro area, while the remainder goes to the RoW sector, is illustrated in Figure 14. Following the transfer of domestic deposits to the global stablecoin, and as $\gamma$ approaches zero, the RoW sector becomes an increasingly dominant node in the network of investment fund shares. The final steps under stage 1, where (i) the RoW sector deposits the surplus (1- $\gamma$ ) of euros in the domestic CB, and (ii) the domestic commercial banks borrow this amount from the central bank to cover their remaining funding gaps, occur in the network of deposits and are shown in Graphs C and D in Figure 11.

Figure 14: Network of Institutional Sectors, Instrument Category Investment Fund Shares, $\mathbf{t = 2 .}$

Panel A: Network of Investment Fund Shares, after Funds Have Shifted to RoW
Panel B: Network of Investment Fund Shares, after RoW Has Shifted a Share of $\gamma$ to INV Sector
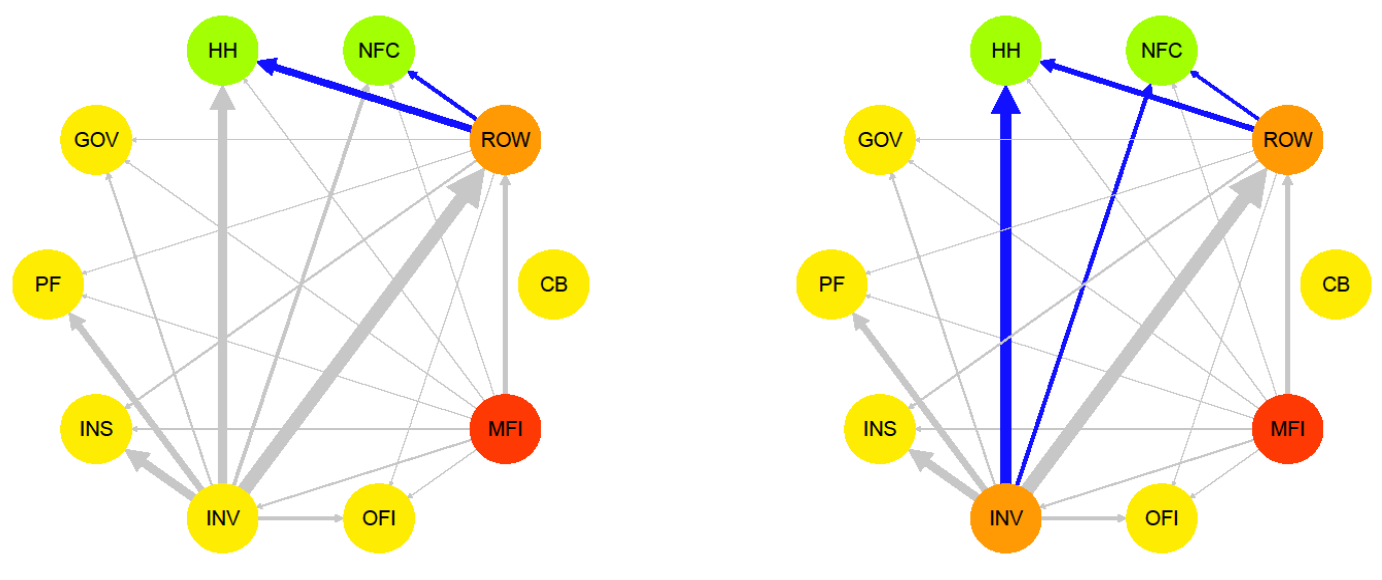

Arrows run from liabilities to assets.

Despite the fact that the digital currency issued by the private stablecoin is in the form of investment fund shares rather than deposits, considering the same set of rebalancing actions (B-D) as earlier means that most of the rebalancing transactions in $t=2$ still occur in marketable securities (bonds). In other words, the process of rebalancing generates shifts in the network of debt securities that are broadly similar to the case where the stablecoin was classified as a deposit scheme (shown in Figure 10). 


\section{Comparative Statics of the Digital Currency Shock}

In this section, we provide further analysis to quantify the economic impact caused by the introduction of the digital currency on the overall financial system. We also consider network metrics and explore the implications of introducing a digital currency at different points in time.

\subsection{Shock Size and Bank Funding}

Retail deposits are a key source of funding for commercial banks (MFI). It is therefore important to evaluate the broader impact on banks of the deposit shift triggered by the introduction of a digital currency. For this, we compute the ratio between the amount that is withdrawn by corporate and household depositors, on the one hand, and the total amount of deposits held by all sectors with commercial banks, on the other:

$$
\text { SHOCK }-M F I=\frac{\text { Deposits }_{M F I, N F C}+\text { Deposits }_{M F I, H H}}{\text { Total Deposits }_{M F I}}
$$

Table 1, column 2 shows the overall impact of the withdrawals on commercial bank deposits, expressed in percentages. In turn, columns 3 and 4 show the respective contributions of the NFC and HH sector withdrawals to the total impact. Under the baseline scenario, where the private non-financial sectors each withdraw $20 \%$ of their bank deposits, the negative impact on the overall MFI deposit stock is limited to around 9\%. Household depositors are the main contributors to this loss. When the size of the deposit shock increases, the overall loss of commercial bank funding also increases. Setting the shock at $80 \%$ of both NFC and HH deposits would cause a loss of $37 \%$ of all commercial bank deposits. Such a large outflow would require far more significant rebalancing and possibly a large-scale recourse to central bank lending facilities at time $t=2$. Columns 5 and 6 show the results of a scenario in which also the RoW sector shifts a share of deposits to a digital currency. In this case the funding shock for MFI would raise to almost $49 \%$. While it might be unreasonable to expect shifts of such magnitude to occur in short periods of time, the exercise nevertheless highlights the importance of the pace and magnitude of the digital currency's potential ability to capture market share in deposits. That said, in the low (even negative) interest rate environment and with younger customers less loyal to traditional banking services, significant changes in deposit patterns may take place if digital currencies were to prove particularly convenient or if they provided additional functions that are appealing to depositors. 
Table 1: The Impact of Deposit Shift on MFI. The table shows the deposit shift as a \% share of the depositing sector's MFI deposits (column 1), the overall reduction in MFI deposits (column 2), and the contributions of NFC (column 3) and $\mathrm{HH}$ (column 4) to the total reduction in deposits. Funding shocks for the case in which also RoW shifts some deposits are shown in columns 5-6. All values are in percentages.

\begin{tabular}{|c|c|c|c|c|c|}
\hline \multirow[b]{2}{*}{ Shock } & \multicolumn{3}{|c|}{ Scenario NFC \& HH withdrawals } & \multicolumn{2}{|c|}{ Scenario NFC, HH \& ROW withdrawals } \\
\hline & Shock-MFI TOTAL $_{\text {T }}$ & Shock-MFI & Shock-MFI ${ }_{H H}$ & Shock-MFI TOTAL $_{\text {Th }}$ & Shock-MFI \\
\hline 10 & 4.57 & 1.12 & 3.46 & 6.12 & 1.54 \\
\hline 20 & 9.15 & 2.23 & 6.91 & 12.23 & 3.09 \\
\hline 30 & 13.72 & 3.35 & 10.37 & 18.35 & 4.63 \\
\hline 40 & 18.29 & 4.47 & 13.83 & 24.47 & 6.18 \\
\hline 50 & 22.86 & 5.58 & 17.28 & 30.59 & 7.72 \\
\hline 60 & 27.44 & 6.70 & 20.74 & 36.70 & 9.27 \\
\hline 70 & 32.01 & 7.82 & 24.19 & 42.82 & 10.81 \\
\hline 80 & 36.58 & 8.93 & 27.65 & 48.94 & 12.36 \\
\hline 90 & 41.16 & 10.05 & 31.11 & 55.06 & 13.90 \\
\hline 100 & 45.73 & 11.16 & 34.56 & 61.17 & 15.44 \\
\hline
\end{tabular}

\subsection{Shock Size and Impact on MFI Rebalancing Strategies}

Next, we explore how changes in the size of the shock affect the impact of commercial banks' rebalancing actions at time $t=2$ on other sectors. We consider two separate MFI rebalancing strategies, where banks can either sell debt securities or redeem loans. We define the impact on sector $i, D S-I_{i}$, as the ratio between the bonds issued by sector $i$ that are sold by the MFI and the total outstanding amount of bonds issued by sector $i$. This measure provides, for all debt issuing sectors, an indicator of the downward pressure on bond prices that would arise in the absence of a corresponding increase in demand by some other sector in the system.

$$
D S-I_{i}=\frac{\text { Debt Securities } \operatorname{SOLD}_{i, M F I}}{\text { Outstanding Debt Securities }_{i}}
$$


To account for the amount of loans that could be redeemed in the MFI rebalancing process, we define LOANS $I_{i}$ as the ratio between the loans extended by banks to sector $i$ but redeemed following the shock and the total outstanding amount of loans extended to sector $i$. The ratio provides a measure of the loan-funding gap for each sector in the absence of new lending by some other sector in the system.

$$
\text { LOANS }-I_{i}=\frac{\text { Redeemed } \operatorname{LOANS}_{i, M F I}}{\text { Outstanding Loans }}
$$

Figure 15 displays this impact of banks' rebalancing strategies for different shock sizes. Panel A shows that the most affected sectors when the banks sell debt securities are the MFI itself, OFI, GOV and RoW. Panel B shows that if the banks redeem loans instead, the most affected sectors are HH, NFC, INV and GOV. Under the baseline scenario of a $20 \%$ deposit withdrawal by both $\mathrm{HH}$ and NFC, even the most affected sectors would experience a relatively limited impact; for example $D S-I_{O F I}$ would amount to $11 \%$ and $L O A N S-I_{H H}$ to $12 \%$. However, if the size of the deposit shift rises to $50 \%$, almost $30 \%$ of all outstanding OFI debt securities would be sold or, alternatively, some $30 \%$ of all loans extended to households would be redeemed.

Figure 15: Impact of MFI Rebalancing Strategies for Different Shock Sizes. Panel A shows the ratio between the debt securities issued by sector $i$ and sold by the MFI, and the total outstanding amount of debt securities issued by sector $i$. Panel B shows the ratio between the amount of loans extended to sector $i$ and redeemed by MFI, and the total outstanding amount of loans extended to sector $i$. The horizontal axis refers to the size of the shock (from $0 \%$ to $100 \%$ ).
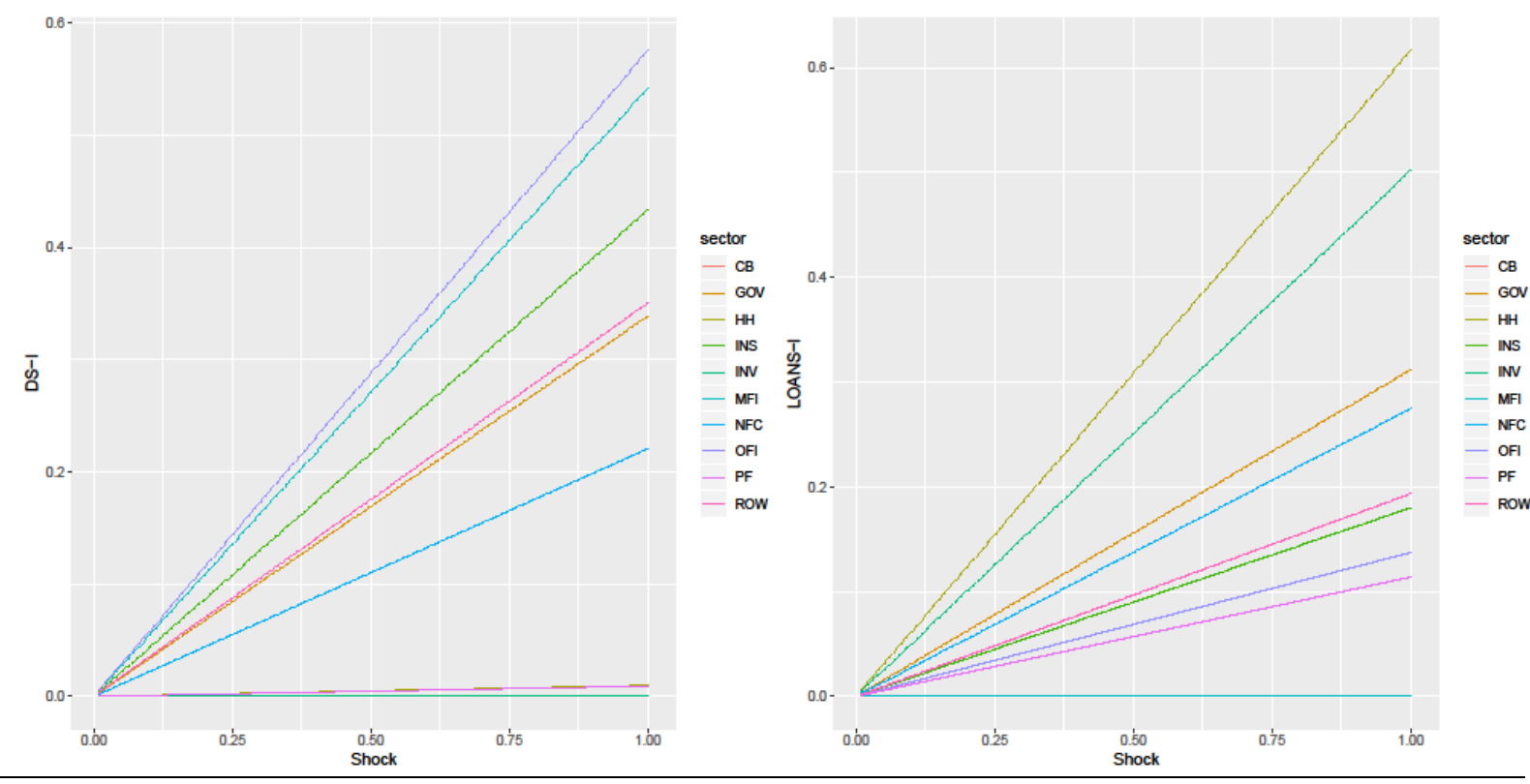


\subsection{Shock Size and Changes in the Macro Network Structure}

We now turn to an investigation of how the structures of the macro-networks change when the size of the shock is allowed to vary. To do this, we first introduce Closeness, a network centrality measure that allows us to quantify the changes in the networks that are triggered by the introduction of the digital currency and the rebalancing process that follows it. Measures of network centrality quantify the position of a given node in the network and provide insights into contagion and diffusion processes. They have been used to investigate the effect of the global financial crisis on the interbank market (Affinito and Pozzolo, 2017), the dynamics of the global banking network (Minoiu and Reyes, 2013) and the relationship between international trade linkages and stock market returns (Kali and Reyes, 2010). ${ }^{21}$ We apply closeness as a measure of how "close" a node is to all the other nodes in the network. Even if the macro-networks considered here consist of only 10 nodes (institutional sectors), closeness can provide indications of how the importance of each sector in the system changes. ${ }^{22}$

For the sake of brevity we focus on the case where the digital currency is classified as a deposit scheme. Drawing from the network of deposits, Figure 16 shows how the closeness measure of the affected sectors varies with the size of the shock in the case of a CBDC (Panel A) and in the case of a stablecoin (Panel B) across the different simulation stages. We consider MFI, which is the most central node at time $t=0$, and the sectors issuing the digital currency. Following the introduction of the CBDC, Panel A (left graph) shows the growing centrality of the central bank as the shock size increases. CB centrality then decreases as the shock size rises after rebalancing at time $\mathrm{t}=2$ (right graph), but it does not reach the pre-shock level. Panel B shows similar patterns for the INV sector (stablecoin). In both cases, the centrality of the MFI sector is lower at $t=2$ than at $t=1$, the more so the larger the shock (right graph).

Importantly, this proves that even in the most conservative scenario, where the MFI borrows the lost deposits back from the digital currency issuing sector, the relative importance of the different sectors and the structure of the "steady state" macro-network change.

\footnotetext{
${ }^{21}$ Other applications include analysis of venture capital firms and fund performance (Hochberg et al., 2007), the effect of CEOs' social connections on M\&A outcomes (El-Khatib et al., 2015), and other corporate finance policy decisions (Fracassi, 2017).

22 We consider the weighted version of closeness to properly take into account changes in the intensity of the financial linkages. By using alternative centrality measures, i.e. eigenvalues, we obtain similar insights.
} 
Figure 16: Network of Deposits: Sector Centrality Measures at Different Simulation Stages. The centrality measure is closeness (normalized). Panel A (B) shows the case of the CBDC (stablecoin) for the issuing sector and the MFI. The $x$-axis measures the size of the shock. The $y$-axis depicts the scale of the centrality measure (closeness). The z-axis shows time (periods $0,1,2$ ).
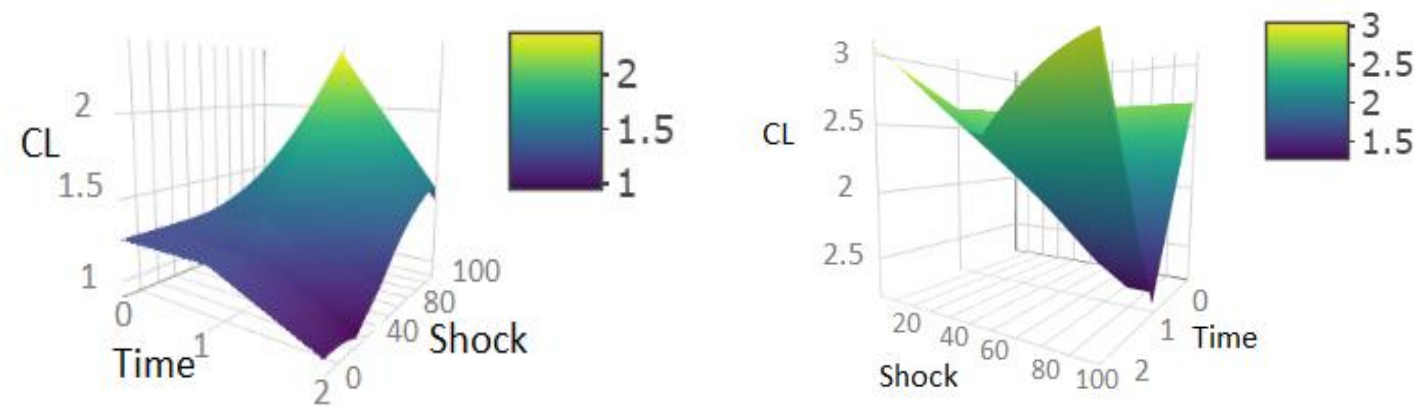

Panel B: INV issuing digital currency

INV

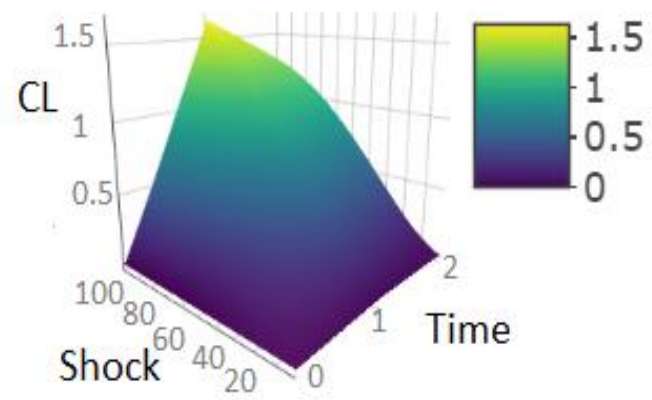

MFI

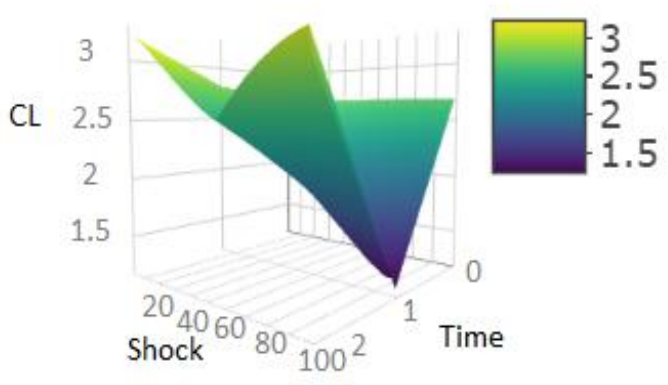




\subsection{Timing of the Introduction of Digital Currency}

Finally, we explore the effects of the introduction of a digital currency over time. The time series covers the period for which data from the who-to-whom accounts are available, i.e. from Q1 2015 to Q1 2019. As a first step, using the metrics introduced in Section 6.1., in Figure 17 we consider the overall funding impact for MFI after a $20 \%$ deposit shock from the NFC and HH sectors (red line) and NFC, HH and RoW sectors (blue line). We notice an increase in the relative contribution of the deposit shift by the NFC sector from 1.9\% in Q1 2015 to 2.2\% in Q1 2019, and by the HH sector from 6.5\% in Q1 2015 to 6.9\% in Q1 2019. The overall impact on MFI deposits of the deposit withdrawal by the private non-financial sectors rises from $8.4 \%$ to $9.1 \%$, while when we consider also the RoW it increases from $11.4 \%$ to $12.2 \%$. The overall growth in impact is not particularly large, but the graph nonetheless highlights how the timing of the introduction of the digital currency could be relevant as the impact is clearly time-varying. Similarly, the impact of MFI rebalancing strategies for the different sectors of the economy also vary and should be taken into account by policy makers and regulators.

Figure 17: Impact of Shock on Overall MFI Deposits Over Time. The chart shows, over time, the ratio between a $20 \%$ deposit withdrawal by the NFC and HH sectors and total MFI deposits (red line), and a 20\% deposit withdrawal by the NFC, HH and ROW sectors and the total MFI deposits (blue line). Period Q1 2015-Q1 2019.

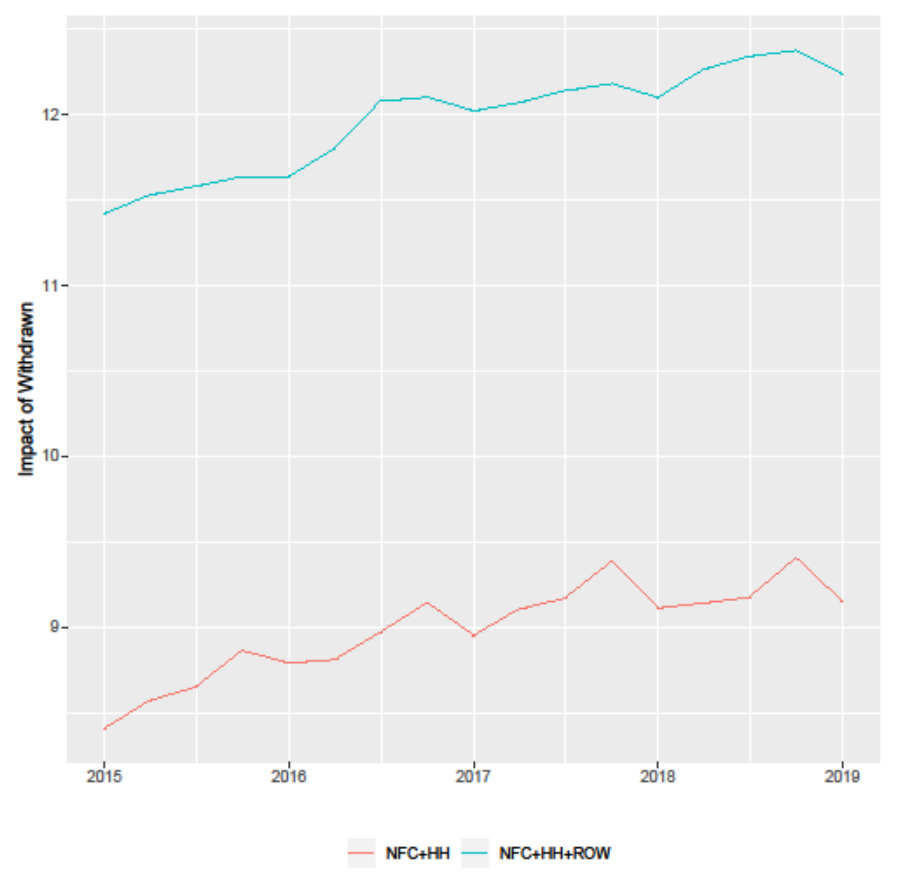

Network centrality measures can be used to illustrate the evolution over time of the shape of the macro-network. In the status quo macro-network of deposits the most important sectors in terms of closeness were the MFI, followed by the $\mathrm{CB}$ and the RoW sectors. Figure 18 focuses on the dynamic pattern of centrality of these three sectors in the status quo network of deposits. While the centrality of both the MFI and RoW sectors has decreased over time, the centrality of the central bank has increased dramatically throughout the past four years, reflecting the Eurosystem's large-scale asset purchase programmes. Network structures may therefore change significantly even over a relatively short periods of time, which means that the "time 0 ", when the digital currency 
is to be launched, could indeed matter. This is because, as was shown earlier in this paper, the ultimate impact of the introduction of a digital currency and the rebalancing that follows it are dependent on the underlying network structures. At certain times and under certain conditions, a digital currency could therefore be more disruptive and potentially undermine financial stability.

Figure 18: Status Quo Network of Deposits: Centrality over Time. The charts show the values of closeness for the MFI (left panel), CB (middle panel), and RoW (right panel) over time. Period Q1 2015-Q1 2019.

MFI

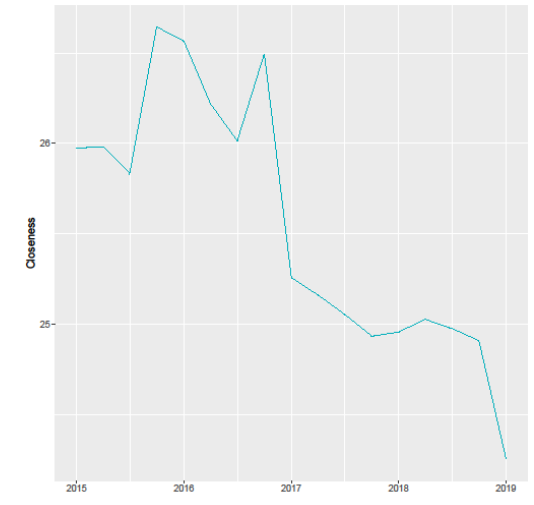

$\mathrm{CB}$

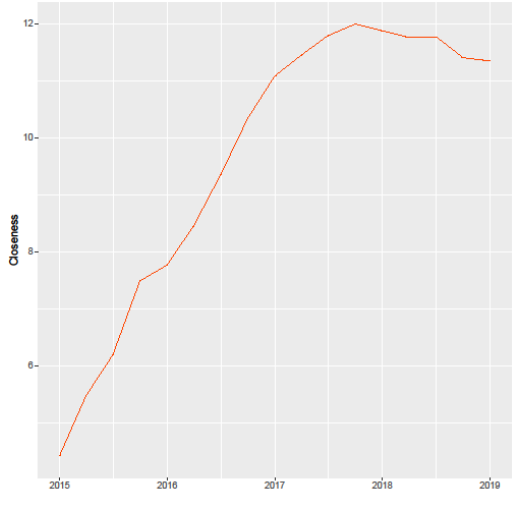

ROW

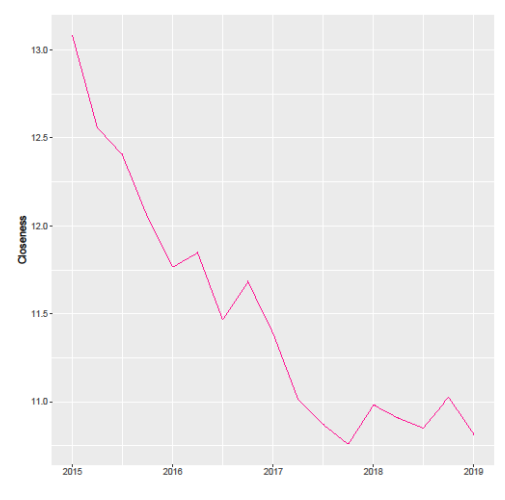




\section{Conclusions}

This paper applied the network approach to financial accounts to study the broader implications of the introduction of digital currencies, a major financial innovation with far-reaching positive consequences. The network approach provides important additional insights into the adjustment processes that may follow from the large-scale adoption of major financial innovations. The following sequence of points summarises our key findings and our contribution from the policy discussion perspective.

(i) Design: the way the digital currency scheme is established (public or private issuer, classified as currency, deposit, security or investment fund share) makes a difference both for the issuing sector, the banking sector, the retail users/depositors and the monetary/regulatory authorities. Specific circumstances may favour certain designs over others.

(ii) Reaction: The ways the affected parties adjust to the introduction of the digital currency by shifting deposits and rebalancing their accounts depend not only on (i) but also on the incentives and constraints/mandates they face. There may be ways to shape these incentives by mechanism design and public policy.

(iii) Third parties: Given that the financial system is a network, third parties will be affected by the introduction of a digital currency and the rebalancing that follows it. The identity of these third parties and the impact they experience may differ depending on how (i) and (ii) play out. Effort should be taken to identify the relevant links and mitigate any potential collateral damage ex ante. $^{23}$

(iv) Timing: The financial network structures that in part determine (i), (ii) and (iii) are not static; rather, they evolve over time as the intensity of the bilateral links change. This means that, at any point in time, the network may be more or less able to diffuse shocks, and therefore the timing of the initiative matters.

Our study also highlighted the strong cross-border links in financial networks. Large-scale domestic digital initiatives may have important repercussions to the international financial system by replacing cross-border exposures with a higher concentration around the domestic providers. On the other hand, successful digital currencies established in major currency areas may become popular in other countries, contributing to the loss of monetary sovereignty as has been highlighted in the literature. We also note that some reallocation of exposures in the macro-networks has already been taking place over the past decade, with the centrality of the central bank increasing sharply in countries where large-scale central bank asset purchases have been taking place. Opening up the central bank balance sheet to non-financial depositors would not quantitatively increase the aggregate exposures except in the case where the central bank would also assume the role of creating new credit to the non-financial sectors. However, it would trigger a re-allocation of funds along the existing links in the network, with uncertain consequences. Such a reform may raise not only regulatory and financial stability issues but also distributionary questions, as well as other fundamental issues related to integrity of data, competition, and public versus private provision of essential financial services. These questions would of course be valid also in the case of large-scale, possibly global, stablecoin initiatives which may face additional issues such as their ability to stabilise the value of the currency against the reserve fund in all states of the world.

\footnotetext{
${ }^{23}$ For example, under certain combinations of (i) and (ii), commercial banks may face a "double whammy" scenario where they both lose deposits and face a sharp deterioration in their wholesale funding conditions.
} 
Our results underline the importance of the full network implications of innovations for financial intermediation. Any shock to the system that causes shifts in the financial balance sheets have the potential to generate a redistribution of financial linkage. These may then force adjustments in financial asset prices which may not be properly captured by analysis that does not consider the full network of interlinked exposures. We also stress that from financial stability perspective, it is important to focus not only on the deposits and other liabilities but also on the impact on the asset sides of the financial institutions balance sheets, and the associated risks for nonfinancial sectors. Bank lending remains a key source of financing for non-financial sectors in many economic areas, such as the EU. The implications of large and potentially abrupt changes in the flow of deposit funds for the efficient allocation of credit to the economy should therefore also be a part of the debate. 


\section{References}

Acemoglu, D., Akcigit, U., and Kerr, W. (2016). "Networks and the macroeconomy: An empirical exploration". NBER Macroeconomics Annual, 30, 273-335.

Adrian, T. and Mancini-Griffoli, T. (2019). "The Rise of Digital Money". IMF Fintech Notes.

Aldasoro, I., and Alves, I. (2018). "Multiplex interbank networks and systemic importance: an application to European data. Journal of Financial Stability, 35, 17-37.

Anderson, J. and F. Papadia (2020). “Libra as a Currency Board: are the Risks too Great?" Blog Post at Bruegel.org, January 272020.

Bargigli, L., Di lasio, G., Infante, L., Lillo, F., and Pierobon, F. (2015). "The multiplex structure of interbank networks". Quantitative Finance, 15, 673-691.

Basel Committee on Banking Supervision (2019). "Designing a Prudential Treatment for Crypto-Assets". Discussion Paper, Basel, Bank for International Settlements.

Bindseil, U. (2020). “Tiered CBDC and the Financial System”. ECB Working Paper No 2351.

Bank for International Settlements (2019). "Big Tech in Finance: Opportunities and Risks". BIS Annual Economic Report pp. 55-75.

Brunnermeier, M., H. James and J.-P. Landau (2019). "The Digitalisation of Money". Mimeo, Princeton University.

Bullmann, D., J. Klemm and A. Pinna (2019). "In Search for Stability in Crypto-Assets: Are Stablecoins the Solution?". ECB Occasional Paper No 230.

Caccioli, F., Shrestha, M., Moore, C., and Farmer, J. D. (2014). "Stability analysis of financial contagion due to overlapping portfolios". Journal of Banking \& Finance, 46, 233-245.

Castrén, O. and I. K. Kavonius (2013). "Balance Sheet Interlinkages and Macro-Financial Risk Analysis in the Euro Area". In: Fouque, J.-P. and Langsam, J. A. (eds.) Handbook of Systemic Risk, Cambridge University Press, pp 775789.

Castrén, O. and M. Rancan (2014). "Macro-Networks: An Application to Euro Area Financial Accounts". Journal of Banking and Finance, 46, pp 43-58.

Committee on Payments and Markets Infrastructures (2018). "Central Bank Digital Currencies". Report by the Markets Committee, Basel, Bank for International Settlements.

Craig, B., and Von Peter, G. (2014). "Interbank tiering and money center banks". Journal of Financial Intermediation, 23, 322-347.

El-Khatib, R., Fogel, K., and Jandik, T. (2015). "CEO network centrality and merger performance". Journal of Financial Economics, 116(2), 349-382.

Financial Stability Board (2019). "Crypto-Assets: Work Underway, Regulatory Approaches and Potential Gaps". Report for G20 Finance Ministers and Central Bank Governors for the June 2019 meeting. 
Fracassi, C. (2017). “Corporate finance policies and social networks”. Management Science, 63, 2420-2438.

G7 Working Group on Stablecoins (2019). "Investigating the Impact of Global Stablecoins”. Basel, Bank for International Settlements.

Gropp, R., and Heider, F. (2010). "The determinants of bank capital structure". Review of finance,14, 587-622.

Hochberg, Y. V., Ljungqvist, A., and Lu, Y. (2007). "Whom you know matters: Venture capital networks and investment performance". Journal of Finance, 62, 251-301.

International Monetary Fund (2018): "Treatment of Crypto Assets in Macroeconomic Statistics", Mimeo, IMF Statistics Department

Kiyotaki, N. and J. Moore (2018). "Inside Money and Liquidity”. Mimeo, Princeton University.

Juks, R. (2018). "When Central Bank Digital Currency Meets Private Money: Effects of an E-Krona on Banks", Sveriges Riksbank Economic Review, 3, pp. 79-99.

Kumhof, M. and C. Noone (2018). "Central Bank Digital Currencies - Design Principles and Balance Sheet Implications", Bank of England Staff Working Paper No 725.

Libra Association (2019). “An Introduction to Libra”, a White Paper by Libra Association Members.

Minoiu, C., and Reyes, J. A. (2013). “A network analysis of global banking: 1978-2010". Journal of Financial Stability, 9, 168-184.

Mistrulli, P. E. (2011). “Assessing financial contagion in the interbank market: Maximum entropy versus observed interbank lending patterns". Journal of Banking \& Finance, 35, 1114-1127.

Organisation for Economic Cooperation and Development (2018). "How to Deal with Bitcoin and Other Cryptocurrencies in the System of National Accounts?", Paper Presented at the OECD Working Party on Financial Statistics.

Peltonen, T. A., Scheicher, M., and Vuillemey, G. (2014). "The network structure of the CDS market and its determinants". Journal of Financial Stability, 13, 118-133.

Poledna, S., Molina-Borboa, J. L., Martínez-Jaramillo, S., Van Der Leij, M., and Thurner, S. (2015). "The multi-layer network nature of systemic risk and its implications for the costs of financial crises". Journal of Financial Stability, $20,70-81$.

Shin, H. S. (2019). "What Are Stablecoins Good For?", Speech at PIIE-Princeton Meeting on the "Future of Money in the Digital Age", Washington DC, October 2019.

Somoza, L. and T. Terracciano (2019). "Stabilising Stablecoins: A Pragmatic Regulatory Approach", Article published on VOX CEPR Policy Portal, December 2019

Stolbova, V., Monasterolo, I., and Battiston, S. (2018). "A financial macro-network approach to climate policy evaluation". Ecological Economics, 149, 239-253.

Upper, C., and Worms, A. (2004). "Estimating bilateral exposures in the German interbank market: Is there a danger of contagion?". European Economic Review, 48, 827-849. 


\section{Annex - The Model}

\section{A.1. The Financial System}

This section sets up the model which we then fit to the EEA data, introduced in Section 2. The financial system consists of $n$ institutional sectors $i, i=1, \ldots, n$, with $n=10$. The liability side of the balance sheet of sector $i$ encompasses $X$ items including quoted and unquoted equity shares (EQ), deposits, credit (loans) and debt securities (DD), other items $(\mathrm{OI})^{24}$ and net wealth (NW), where the latter is defined as total assets minus total liabilities. Formally, we have:

$L_{i, t}=E Q_{i, t}{ }^{L}+D D_{i, t}{ }^{L}+O I_{i, t}{ }^{L}+N W_{i, t}$

where the superscripts $L$ denote liability items and $D D_{i, t}{ }^{L}=\sum_{j=1}^{n} \omega_{i, j, t}^{D} D_{i, t}^{L}+\sum_{j=1}^{n} \omega_{i, j, t}^{B} B_{i, t}^{L}+\sum_{j=1}^{n} \omega_{i, j, t}^{C} C_{i, t}^{L}$ is a portfolio of debt items deposits $\left(D^{L}\right)$, bonds $\left(B^{L}\right)$ and credit $\left(C^{L}\right)$, with weights determined by $\omega$. The asset side of sector $i$ is defined as:

$A_{i, t}=E Q_{i, t}{ }^{A}+D D_{i, t}{ }^{A}+O I_{i, t}{ }^{A}$,

where superscripts $A$ denote asset items and $E Q_{i, t}{ }^{A}=\sum_{j=1}^{n} \omega_{i, j, t}^{E Q}\left(E Q_{i, t}^{L}\right), D D_{i, t}{ }^{A}=\sum_{j=1}^{n} \omega_{i, j, t}^{D D}\left(D D_{i, t}^{L}\right)$ and $O l_{i, t}{ }^{A}=$ $\sum_{j=1}^{n} \omega_{i, j, t}^{O I}\left(O I_{i, t}^{L}\right)$ are portfolios of equity, debt and other assets issued by all sectors $j$, including sector $i$ itself.

At the financial system level, with the rest of the world sector, we have:

$\sum_{i=1}^{n} L_{i, t}=\sum_{i=1}^{n} A_{i, t}$ and $\sum_{i=1}^{n} N W_{i, t}=0$

\footnotetext{
24 The largest items in the "Other Items" category are liabilities associated with insurance companies (pre-paid insurance premiums), pension funds (paid pension liabilities) as well as money market and investment fund shares. The counterparty sectors to the first two types of items on the asset side are mainly households and non-financial corporations, and for the latter items households and MFIs.
} 
The latter condition means that even if the net wealth positions may be non-zero at sector level, at the financial system level they cancel out. If the domestic sectors in aggregate show a positive (negative) net wealth position, this will be reflected by an offsetting current account surplus (deficit) position vis-à-vis the rest of the world. ${ }^{25}$

Following Castrén and Kavonius (2013) and Castrén and Rancan (2014), we then represent the financial system as a macro-network. The macro-network consists of a set of bilateral links between the institutional sectors which constitute the nodes of the network. The links of the network are the EAA who-to-whom statistics for the different financial instruments. Formally, $\omega_{i, j, t}^{X} X_{i, t}$ corresponds to a link from sector $i$ to sector $j$ at time $t$, for instrument $X$. Separate macro-networks are drawn for the different financial instruments. The macro-network allows us to model the financial system as an intertwined set of agents that is particularly suitable to account for shock propagation and feedback effects. ${ }^{26}$

\section{A.2. The Issuance of a Digital Currency}

Next, we assume that at time $t+1$, the digital currency is issued, depending on the particular design and institutional classification of the scheme, either by the central bank (CB), the investment funds sector (INV), or the rest of the world sector (ROW). The introduction of the digital currency implies a shock $\xi^{D}$ in the form of a switch of deposits by both households $(\mathrm{HH})$ and non-financial corporations (NFC) ${ }^{27}$ from MFI to the sector $y$ hosting the digital currency, with $y \in\{C B, I N V, R O W\}$. Formally:

$$
\begin{aligned}
& L_{M F I, t+1}=E Q_{M F I, t+1}{ }^{L}+\left(D D_{M F I, t+1}{ }^{L}-\xi^{D}\right)+O I_{M F I, t+1}{ }^{L}+N W_{M F I, t+1} \\
& L_{y, t+1}=E Q_{y, t+1}{ }^{L}+\left(D D_{y, t+1}{ }^{L}+\xi^{D}\right)+O I_{y, t+1}{ }^{L}+N W_{y, t+1}
\end{aligned}
$$

Next, we make a distinction between two possible functions of a digital currency. On the one hand, the digital currency may serve only as a means of payment (a payment instrument that facilitates transactions between agents, possibly cross-border). In that case, after the payment transaction has been completed, the agents in the $\mathrm{HH}$ and/or the NFC sectors convert their digital currency back into commercial bank deposits, or cash. In other words, the shock $\xi^{D}$ is reversed in period $t+2$ and the liability positions of the affected sectors then look as follows:

\footnotetext{
${ }^{25}$ The domestic sectors that typically show negative net wealth positions (i.e. they are net borrowers in the system) are the government and the non-financial corporate sectors. The main surplus, or creditor, sector is the households. The financial sectors are mostly financial intermediaries and tend to have nearly balanced net wealth positions.

${ }^{26}$ There is now an extensive body of literature on financial networks. In their study of bank runs, Allen and Gale (2000) demonstrated the different contagion effects implied by complete versus incomplete network structures. Several papers study contagion effects across financial institutions, using interbank loans as financial links (e.g., Upper and Worms, 2004; Gai and Kapadia, 2010; Mistrulli, 2011; Glasserman and Young, 2015). Some authors have considered a broader set of interlinkages between banks, both on the asset and the liability side, with the aim of better characterizing the way in which financial institutions are connected to each other (Aldasoro and Alves, 2018; Poledna et al., 2015; Bargigli et al., 2015; Caccioli et al., 2014). Papers that investigate network structures and their properties include Craig and von Peter (2014) and Peltonen et al. (2014). Departing from the micro-level analysis, some authors treat the network nodes as more aggregate entities, such as countries (see, e.g., Kali and Reyes, 2010) or industries (see, e.g., Acemoglu et al., 2016).

${ }^{27}$ We consider HH and NFC as the sectors moving their deposits because they are likely to be the main target "clients" of the digital currency. However, our setting is independent of the specific sectors that shift the deposits.
} 


$$
\begin{aligned}
& L_{M F I, t+2}=E Q_{M F I, t+2}{ }^{L}+\left(D D_{M F I, t+2}{ }^{L}+\xi^{D}\right)+O I_{M F I, t+2}{ }^{L}+N W_{M F I, t+2} \\
& L_{y, t+2}=E Q_{y, t+2}{ }^{L}+\left(D D_{y, t+2}{ }^{L}-\xi^{D}\right)+O I_{y, t+2}{ }^{L}+N W_{y, t+2}
\end{aligned}
$$

By contrast, the digital currency may also serve as a store of value, in which case the shifts in exposures may become permanent. If we assume that the sectors will not absorb the shock in their net wealth positions, i.e. $N W_{i, t+2}=N W_{i, t+1}=N W_{i}$, then, at $t+2$ we have, for sector $y$ :

$A_{y, t+1}=E Q_{y, t+1}^{A}+\left(D D_{y, t+1}^{A}+\xi^{D}\right)+O I_{y, t+1}^{A}$

We assume that to offset the increase in its deposit liabilities, the sector issuing the digital currency may choose one of the following options:

$$
\begin{array}{ll}
\text { i) } & A_{y, t+2}=E Q_{y, t+2}{ }^{A}+\left(D D_{y, t+1}{ }^{A}+\delta D^{A}\right)+O I_{y, t+2}{ }^{A} \\
\text { ii) } & A_{y, t+2}=E Q_{y, t+2}{ }^{A}+\left(D D_{y, t+1}{ }^{A}+\delta B^{A}\right)+O I_{y, t+2}{ }^{A} \\
\text { iii) } & A_{y, t+2}=E Q_{y, t+2}{ }^{A}+\left(D D_{y, t+1}{ }^{A}+\delta C^{A}\right)+O I_{y, t+2}{ }^{A}
\end{array}
$$

With $\delta D^{A}=\delta B^{A}=\delta C^{A} \equiv \xi^{D}$. Option (i) means that sector $y$ redeposit the funds with the commercial banks (MFIs). Undern option (ii), sector $y$ purchases debt securities to offset its increase in investible funds. Under option (iii), the sector issuing the digital currency treats the deposits as loanable funds and extends credit (loans).

On the other hand, to offset the reduction in its deposit liabilities the MFI sector may, either:

$$
\begin{array}{ll}
\text { (i) } & L_{M F I, t+2}=E Q_{M F l, t+2}+\left(D D_{M F I, t+1}{ }^{L}+\delta D^{L}\right)+O I_{M F I, t+2}{ }^{L} \\
\text { (ii) } & A_{M F I, t+2}=E Q_{M F I, t+2}{ }^{A}+\left(D D_{M F l, t+1}{ }^{A}-\delta B^{A}\right)+O I_{M F I, t+2}{ }^{A}, \\
\text { (iii) } & A_{M F I, t+2}=E Q_{M F I, t+2}{ }^{A}+\left(D D_{M F l, t+1}{ }^{A}-\delta C^{A}\right)+O I_{M F l, t+2}{ }^{A}, \\
\text { (iv) } & L_{M F I, t+2}=E Q_{M F l, t+2}{ }^{L}+\left(D D_{M F I, t+1}{ }^{L}+\delta B^{L}\right)+O I_{M F I, t+2}{ }^{L}
\end{array}
$$

Where $\delta D^{L}=\delta B^{A}=\delta C^{A}=\delta B^{L} \equiv \xi^{D}$. The response by the MFI may be in the form of an increase in the deposit liability portfolio (receiving re-deposited funds from sector $y, \delta D^{L}$ ), a reduction in the bond asset portfolio $\left(\delta B^{A}\right)$, a reduction in the bank credit asset portfolio $\left(\delta C^{A}\right)$, or an increase in the bond liability portfolio (new issuance, $\left.\delta B^{L}\right)$. Crucially, although the sizes of the various portfolio shifts by MFI are equal to the portfolio shifts by sector $y$, the compositions of the asset portfolios are different. The assets sold/liabilities issued by MFI and the assets purchased by sector $y$ are not identical, and the transactions may therefore require price adjustments to allow 
the markets to clear. ${ }^{28}$ In reality, the actions taken by sectors $y$ and MFI are likely to be some combination of the options above. Moreover, the changes in bilateral exposures at $t+2$ may trigger further adjustments in the system (e.g. the sector that loses bank financing under MFI options (ii) and (iii) at time $t+2$ could replace it by issuing its own debt securities).

${ }^{28}$ While we do not explicitly model prices, our analysis below provides insights about the sectors whose securities will be most affected in different scenarios. 
DIGITAL CURRENCIES IN FINANCIAL NETWORKS 


\section{ACKNOWLEDGEMENTS}

We thank Ulrich Bindseil, Elisabeth Noble and an anonymous referee for useful comments. The opinions and views expressed in this paper are those of the authors only and should not be associated with the EBA.

\section{Olli Castrén:}

European Banking Authority, Paris, France. olli.castren@eba.europa.eu

\section{Ilja Kristian Kavonius:}

Centre for Consumer Society Research, University of Helsinki, Helsinki, Finland. ilja.kavonius@helsinki.fi

\section{Michela Rancan:}

Università Politecnica delle Marche, Ancona, Italy.m.rancan@univpm.it

\section{EUROPEAN BANKING AUTHORITY}

20 avenue André Prothin CS 30154

92927 Paris La Défense CEDEX, France

Tel. +33186527000

E-mail: info@eba.europa.eu

https://eba.europa.eu/

C European Banking Authority, 2020.

Any reproduction, publication and reprint in the form of a different publication, whether printed or produced electronically, in whole or in part, is permitted, provided the source is acknowledged. Where copyright vests in a third party, permission for reproduction must be sought directly from the copyright holder. 